\title{
Spatial patterns in the contribution of biotic and abiotic factors to the population dynamics of three freshwater fish species
}

\author{
Mathieu Chevalier $^{\text {Corresp., } 1}$, Pablo Tedesco ${ }^{2}$, Gael Grenouillet ${ }^{2}$ \\ ${ }^{1}$ Centre de Bretagne, DYNECO, Laboratoire d'Ecologie Benthique Côtière (LEBCO), IFREMER, Plouzané, France \\ 2 Laboratoire Évolution \& Diversité Biologique (EDB), CNRS 5174, IRD 253, Université de Toulouse, Toulouse, France \\ Corresponding Author: Mathieu Chevalier \\ Email address: mathieu.chevalier@ifremer.fr
}

\section{Background}

Population dynamics are driven by a number of biotic (e.g. density-dependence) and abiotic (e.g. climate) factors whose contribution can greatly vary across study systems (i.e. populations). Yet, the extent to which the contribution of these factors varies across populations and between species and whether spatial patterns can be identified has received little attention.

Methods Here, we used a long-term (1982-2011), broad scale (182 sites distributed across metropolitan France) dataset to study spatial patterns in the population's dynamics of three freshwater fish species presenting contrasted life-histories and patterns of elevation range shifts in recent decades. We used a hierarchical Bayesian approach together with an elasticity analysis to estimate the relative contribution of a set of biotic (e.g. strength of density dependence, recruitment rate) and abiotic (mean and variability of water temperature) factors affecting the site-specific dynamic of two different size classes $\left(0^{+}\right.$and $>0^{+}$ individuals) for the three species. We then tested whether the local contribution of each factor presented evidence for biogeographical patterns by confronting two non-mutually exclusive hypotheses: the "range-shift" hypothesis that predicts a gradient along elevation or latitude and the "abundant-center" hypothesis that predicts a gradient from the center to the edge of the species' distributional range.

Results Despite contrasted life-histories, the three species displayed similar large-scale patterns in population dynamics with a much stronger contribution of biotic factors over abiotic ones. Yet, the contribution of the different factors strongly varied within distributional ranges and followed distinct spatial patterns. Indeed, while abiotic factors mostly varied along elevation, biotic factors - which disproportionately contributed to population dynamics - varied along both elevation and latitude.

Conclusions Overall while our results provide stronger support for the range-shift hypothesis, they also highlight the dual effect of distinct factors on spatial patterns in population dynamics and can explain the overall difficulty to find general evidence for geographic gradients in natural populations. We propose that considering the separate contribution of the factors affecting population dynamics could help better understand the drivers of abundance-distribution patterns. 


\section{Spatial patterns in the contribution of biotic and abiotic}

\section{2 factors to the population dynamics of three freshwater fish}

\section{3 species}

4

5 Mathieu CHEVALIER ${ }^{1}$, Pablo A. TEDESCO ${ }^{2}$ and Gaël GRENOUILLET ${ }^{2}$

6

$7{ }^{1}$ IFREMER, Centre de Bretagne, DYNECO, Laboratoire d'Ecologie Benthique Côtière

8 (LEBCO), 29280 Plouzané, France.

$9{ }^{2}$ Laboratoire Évolution \& Diversité Biologique (EDB), Université de Toulouse, CNRS 5174,

10 IRD 253, Université Toulouse 3 - Paul Sabatier, 118 route de Narbonne, F-31062 Toulouse,

11 France

12

13 Corresponding author:

14 Mathieu Chevalier

151625 Route de Sainte-Anne, 29280 Plouzané, France

16 Email address: mathieu.chevalier38@gmail.com 


\section{Abstract}

18

19

20

21

22

23

\section{Background}

Population dynamics are driven by a number of biotic (e.g. density-dependence) and abiotic (e.g. climate) factors whose contribution can greatly vary across study systems (i.e. populations). Yet, the extent to which the contribution of these factors varies across populations and between species and whether spatial patterns can be identified has received little attention.

\section{Methods}

Here, we used a long-term (1982-2011), broad scale (182 sites distributed across metropolitan France) dataset to study spatial patterns in the population's dynamics of three freshwater fish species presenting contrasted life-histories and patterns of elevation range shifts in recent decades. We used a hierarchical Bayesian approach together with an elasticity analysis to estimate the relative contribution of a set of biotic (e.g. strength of density dependence, recruitment rate) and abiotic (mean and variability of water temperature) factors affecting the site-specific dynamic of two different size classes $\left(0^{+}\right.$and $>0^{+}$individuals $)$for the three species. We then tested whether the local contribution of each factor presented evidence for biogeographical patterns by confronting two non-mutually exclusive hypotheses: the "rangeshift" hypothesis that predicts a gradient along elevation or latitude and the "abundant-center" hypothesis that predicts a gradient from the center to the edge of the species' distributional range.

\section{Results}

Despite contrasted life-histories, the three species displayed similar large-scale patterns in population dynamics with a much stronger contribution of biotic factors over abiotic ones. Yet, the contribution of the different factors strongly varied within distributional ranges and followed distinct spatial patterns. Indeed, while abiotic factors mostly varied along elevation, biotic factors 
40 - which disproportionately contributed to population dynamics - varied along both elevation and

41 latitude.

\section{Conclusions}

43 Overall while our results provide stronger support for the range-shift hypothesis, they also

44 highlight the dual effect of distinct factors on spatial patterns in population dynamics and can

45 explain the overall difficulty to find general evidence for geographic gradients in natural

46 populations. We propose that considering the separate contribution of the factors affecting

47 population dynamics could help better understand the drivers of abundance-distribution patterns. 
Population dynamics have been related to several factors that can be classified as intrinsic (i.e.

50 biotic) or extrinsic (i.e. abiotic) (Cappuccino \& Price, 1995). Whether populations are mostly influenced by one or the other type of factor has been a matter of debate (Andrewartha \& Birch, 1954; Nicholson, 1957) and has recently regain interest owing to the need to improve our knowledge regarding the influence of climate change on population and species extinction risk (Bellard et al., 2012). Although there is now clear evidence that both factors can influence wild populations (Bjørnstad \& Grenfell, 2001), we still have a poor understanding of their relative influence across the distributional range of species (Frederiksen, Harris \& Wanless, 2005; Guo et al., 2005; Pearce-higgins et al., 2015; Dallas, Decker \& Hastings, 2017; Pironon et al., 2017). Beyond data limitations (i.e. the need of long-term time series for multiple populations), the complexity underlying population dynamics may explain this lack of knowledge (Benton, Plaistow \& Coulson, 2006). For instance, in stage-structured populations, individuals in different states can be differentially influenced by climatic conditions (Coulson et al., 2001; Ibáñez et al., 2015) while contributing differently to the overall dynamic of the population (Radchuk, Turlure \& Schtickzelle, 2013). At the same time, climate can have various influences on populations depending on their position within the distributional range of species (Curnutt, Pimm \& Maurer, 1996; Sæther et al., 2008; Pearce-Higgins et al., 2015). Some studies have attempted to identify the large-scale drivers of population dynamics by studying the extent to which spatially distant populations tend to vary in synchrony over time (Liebhold, Koenig \& Bjørnstad, 2004). While in some cases, their findings support the view of a common climatic driver (e.g. temperature) affecting populations abundance similarly, in most cases, a considerable amount of variance remains unexplained (Chevalier et al., 2015), suggesting that population dynamics and their 
71 associated drivers can greatly vary over space (Sæther et al., 2008; Grøtan et al., 2009; Roy,

72 McIntire \& Cumming, 2016).

73 Spatial differences in population dynamics can vary according to a number of factors

74 including species range limits (Williams et al. 2003), the abiotic environment (Sæther et al.

75 2008), resource availability (Wang et al. 2008), latitude (Sæther et al., 2008; Pearce-higgins et

76 al., 2015) or elevation (Dostálek, Rokaya \& Münzbergová, 2018). Two main hypotheses have

77 been advanced to explain these spatial variations. Based on the niche concept (Hutchinson, 1957;

78 Peterson et al., 2011), the first hypothesis predicts a negative relationship between population

79 abundance and the distance to the geographic range center (Brown, 1984). This abundant-center

80 hypothesis (also called core-periphery hypothesis; Pironon et al., 2017) has a long-standing

81 history in ecology and assumes that environmental conditions become harsher towards the limits

82 of species ranges, leading to geographic patterns in the demographic performance, the strength of

83 density-dependence or the genetic variability of populations (Sagarin, Gaines \& Gaylord, 2006).

84 For instance, a main expectation is that core populations should be rather regulated by density-

85 dependent processes because highly productive areas tend to be monopolized by individuals with

86 high competitive abilities, whereas peripheral populations are rather expected to be regulated by

87 abiotic factors (Pironon et al., 2017; Santini et al., 2019). However, recent studies found

88 contrasting empirical support for the abundant-center hypothesis casting doubts about its

89 generality (Dallas, Decker \& Hastings, 2017; Santini et al., 2019). The second hypothesis - the

90 range-shift hypothesis - is based on the evidence that species are moving poleward or upward to

91 track suitable climatic conditions (Parmesan \& Yohe, 2003; Pecl et al., 2017). These range shifts

92 imply that populations located at the periphery of the range can display various behaviors

93 depending on whether they are located at the trailing (i.e. low latitude or elevation) edge where 
94 extinction processes are at play (Kuussaari et al., 2009) or at the leading (i.e. high latitude or

95 elevation) edge where colonization processes should be more prevalent (Engler et al., 2009).

96 Different spatial patterns are expected under this hypothesis. For instance, while trailing and

97 leading-edge populations should be both weakly regulated by density-dependent processes owing

98 to environmental disequilibrium, populations located at the leading edge are expected to be

99 positively affected by climate change, whereas the opposite is expected for populations located at

100 the trailing edge (Mills et al., 2017). Whether spatial variations in population dynamics are best

101 explained by the abundant-center or the range-shift hypothesis remains unexplored to date.

102 In this study, we used an extensive database containing information on population

103 abundances and individual sizes from different sites covering France, to study the spatial pattern

104 in the contribution of biotic and abiotic (temperature-related) factors to the population dynamics

105 of three freshwater fish species presenting contrasted life-histories and patterns of range-shifts

106 (see below). We used length frequency histograms (Cattanéo \& Lamouroux, 2002; Bergerot \&

107 Cattanéo, 2017) to separate individuals into two size-classes corresponding to young-of-the-year

$108\left(0^{+}\right)$and older individuals $\left(>0^{+}\right)$. This allowed us to study spatial variations regarding the strength

109 of density dependence between $>0^{+}$individuals (owing to competition for resources), the

110 productivity rate of $>0^{+}$individuals (i.e. an equivalent of the population growth rate but tailored

111 to this particular size-class), the apparent recruitment rate of $0^{+}$individuals (which depends on

112 the density of $>0^{+}$individuals) and the apparent survival rate of $0^{+}$individuals (Grenouillet et al.,

113 2001). Regarding abiotic factors, we focused on the effect of temperature, a factor known to be a

114 strong determinant of the abundance of $0^{+}$individuals (Grenouillet et al., 2001) and year-class

115 strength (i.e. the number of larvae hatched in a given year) and which is therefore classically

116 considered as the most important factor in fish ecology (Mills \& Mann, 1985). However, while 
117 previous studies mostly focused on changes in average temperature, here we also considered the

118 effect of changes in temperature variability; a component predicted to be strongly affected by

119 climate change (Lawson et al., 2015). We used Bayesian inference to estimate model parameters

120 affecting each species population dynamics and elasticity analysis to highlight the relative

121 contribution of biotic and temperature-related factors to the population dynamics of the three

122 species (Koons et al., 2015). From elasticity measures, we then asked the following questions: (i)

123 is the contribution of biotic and temperature-related factors similar across species presenting

124 different life-histories, (ii) can we identify a spatial pattern in the contribution of the different

125 factors and if so (iii) which of the range-shift or the abundant-center hypothesis best explains the

126 observed pattern? The two latter questions were tackled through a model selection procedure

127 testing differences between a null model (assuming no spatial pattern), a model that includes the

128 distance to the geographic center as a covariate (abundant-center hypothesis) and two models

129 that either included latitude or elevation as covariates (range-shift hypothesis). To the best of our

130 knowledge, this study is the first using data from a monitoring program together with a

131 modelling framework integrating elasticity analyses to derive inferences about the drivers of

132 spatial variations in population dynamics, while accounting for stage-specific dynamics.

\section{Materials and Methods}

\section{Datasets}

\section{Studied species}

137 We considered three species presenting different life-history strategies and patterns of

138 elevational range shifts: the barbel (Barbus barbus), the roach (Rutilus rutilus) and the chub 
139 (Squalius cephalus) (Table 1). Following the three demographic strategies proposed by

140 Winemiller (1992), the barbel is an 'equilibrium' strategist characterized by a long lifespan, a

141 low fecundity and a large body size (Kottelat \& Freyhof, 2007; Froese \& Pauly, 2021), the roach

142 is an 'opportunistic' strategist characterized by a small size and a low fecundity whereas the

143 chub has the opposite characteristics and can be considered a 'periodic' strategist. The

144 opportunistic strategy should maximize the colonizing capability of species in stochastic

145 environments with frequent changes at small temporal and spatial scales. Alternatively, a

146 periodic strategy is favored in environments with large scale cyclic variations (e.g. seasonal

147 environment), whereas an equilibrium strategy is favored in environments with low temporal

148 variation in habitat quality and strong biotic interactions (Winemiller, 1992).

149 These differences are expected to entail variations in the direction of the effect and the

150 relative contribution of biotic and temperature-related factors to the population dynamics of the

151 three considered species. For instance, while the abundance of all three species is expected to be

152 positively affected by water temperature (Mills \& Mann, 1985; Grenouillet et al., 2001; Piffady

153 et al., 2010), we expect the barbel to show a stronger regulation by density, particularly for

154 populations located at the center of the range, while the two other species are expected to be

155 rather regulated by temperature-related factors with an increasing negative contribution as the

156 distance to the geographic center increases (Williams, Ives \& Applegate, 2003). Similarly, we

157 expect temperature variability to have a larger positive contribution on roach abundances

158 (opportunistic strategy) than on the abundance of the two other species where average

159 temperature could have a stronger (and positive) influence (Winemiller \& Rose, 1992).

160 The three species also present different patterns of elevational range shifts in the last

161 decades (Comte \& Grenouillet, 2013), with different responses observed along the elevational 
162 gradient (Table 1). For instance, the leading edges (high-elevation populations) of barbel and

163 roach have shifted downward, whereas an upward shift was recorded for chub (Table 1). Thus, a

164 positive influence of temperature is expected for high-elevation populations of chub while the

165 opposite is expected for the two other species. The trailing edges (low-elevation populations) of

166 the three species have been observed to shift upward but at a different pace. The larger shift

167 observed for barbel (Table 1) could be associated with a stronger and negative contribution of

168 temperature for low-elevation populations.

169

170

Species data

171 Fish population abundances and individual sizes were extracted from the freshwater fish

172 monitoring database of the French Biodiversity Office (OFB, http://www.image.eaufrance.fr).

173 We selected 182 sites where data was collected between 1982 and 2011 (3143 sampling

174 operations) by electrofishing. Streams were sampled by wading, during periods of low flow

175 (from May to October), after the reproduction time, using a point sampling strategy covering the

176 different habitats (e.g. pools, riffles, submerged vegetation) observed over the study sites (Poulet,

177 Beaulaton \& Dembski, 2011). Fish were identified to species level, measured for total body

178 length, counted, and released to the river. For the three species, we selected time series that were

179 composed of at least 15 years of data during which the sampling protocol remained the same and

180 contained at least $50 \%$ of non-null captures at the population level (i.e. $0^{+}$and $>0^{+}$individuals

181 confounded). This selection was made to reduce the number of zeroes while keeping times series

182 of sufficient length to allow for an appropriate estimation of the temporal dynamic of

183 populations. We further discarded time series with more than three consecutive years missing to

184 ensure that the loss of information in population change during the missing years is minimized 
185 (Engen et al., 2005). Missing values were ignored during the modelling process. This selection

186 process ensures reliable model inference and left us with 71 (mean length=17.09 years), 175

187 (mean length=17.24 years) and 152 (mean length=17.26 years) time series for barbel, chub and

188 roach, respectively. In total, 326,234 individuals were collected. Further details about abundance

189 and size data are provided in the supplementary material (Appendix S1; Fig. S1 and S2).

190

191 Temperature data

192 Daily air temperatures from 1982 to 2011 were provided by Météo France and extracted from the

193 high resolution ( $8 \mathrm{~km}$ by $8 \mathrm{~km}$ grid) SAFRAN atmospheric analysis over France (Le Moigne,

194 2002). Daily water temperature data measured from 2009 to 2012 at 135 sites located throughout

195 France were provided by the French Biodiversity Office (https://ofb.gouv.fr/). From these two

196 datasets, we used a random forest algorithm where we modelled model water temperature as a

197 function of three covariates: air temperature, month and elevation. The model showed a very

198 good performance and was therefore used to predict daily water temperatures for all sampling

199 sites over the course of the study period. For further details see Chevalier et al., (2018). From

200 daily predictions, we calculated the annual mean and intra-annual variability of water

201 temperature between consecutive sampling occasions at each site and used these temperature

202 variables as covariates in the population dynamic models. For each species, a summary of both

203 variables is provided in the supplementary material (Appendix S1; Fig. S3). These variables

204 were transformed to z-scores before model fitting to improve model convergence. 205 
207 The above-mentioned abundance data do not encompass the full geographic range of the species,

208 potentially leading to niche truncation issues and biased location of geographic range centers

209 (Knouft, 2018; Soberón, Townsend Peterson \& Osorio-Olvera, 2018; Dallas, Pironon \& Santini,

210 2020). To obtain an unbiased estimate of the location of range centers, we used IUCN range

211 maps (https://www.iucnredlist.org/resources/spatial-data-download). Specifically, for each

212 species, we computed its geographic range center as the center of IUCN polygons (based on

213 geographic coordinates) using the gCentroid function of the package rgeos (Bivand \& Rundel,

214 2018). A graphical representation of species range polygons and associated geographic centers is

215 provided in Fig. 4.

216

217 Statistical analyses

218 The modelling workflow (Fig. 1) can be decomposed in four steps, where (1) abundance data are

219 determined for each size class based on individuals' length measured at each sampling operation,

220 (2) the dynamic of the two size-classes is modelled using Bayesian inference, (3) an elasticity

221 analysis is conducted to estimate the contribution of biotic and temperature-related factors on the

222 dynamic of each size class, and (4) a model selection procedure is conducted to investigate the

223 spatial pattern in the contribution of the different parameters and determine whether this pattern

224 rather corresponds to the range-shift or the abundant-center hypothesis. 
227 For each species, we used the length-frequency histograms of each sampling event to separate

228 individuals into two size classes (Bergerot \& Cattanéo, 2017) using Gaussian components

229 (McLachlan \& Peel, 2004). This algorithm assumes that length data can be described by a

230 mixture of two normal distributions which correspond in our case to the length frequency

231 distributions of $0^{+}$and $>0^{+}$individuals. The parameters of the two distributions were estimated

232 using an expectation-maximization algorithm and the limit between the two size classes was

233 fixed at the length where the two distributions crossed. However, because the algorithm

234 performed poorly when the separation between the two size classes was not evident, e.g. when

235 there were few individuals in each group, this procedure cannot be routinely applied to

236 discriminate $0^{+}$and $>0^{+}$individuals for each sampling operation. Therefore a few additional steps

237 had to be considered (see Fig. 1; left column). For each species, we first selected 20 length-

238 frequency histograms for which the discrimination between the two size classes was visually

239 clear and assigned each individual to the $0^{+}$or $>0^{+}$group based on the estimated length limit

240 (Fig. 1). To discriminate $0^{+}$from $>0^{+}$individuals for the remaining sampling events, we used a

241 random forest approach (Liaw \& Wiener, 2002) where individual status $\left(0^{+}\right.$or $\left.>0^{+}\right)$was modeled

242 as a function of individual size, individual numbers (to account for potential effects of density

243 dependence) and annual cumulative degree-days where the water temperature was above $12^{\circ} \mathrm{C}$

244 (i.e. the temperature below which growth is assumed inhibited; Nunn et al., 2003). The model

245 was calibrated using the 20 sampling events for which individual status was assumed unbiased.

246 The predictive performance of our model was tested by running a split-sample cross-validation

247 procedure 100 times. This procedure revealed a very good model performance in predicting

248 individual status, as measured with the Cohen's kappa coefficient ( $\kappa>0.99$ for the three species; 
249 Cohen, 1960). We therefore used this model to predict individual's status for the remaining

250 sampling events. For each species, individuals in each size class were summed for each sampling

251 event to obtain abundance time series (Appendix S1; Fig. S2).

252

253

\section{Population dynamics model}

254 The abundance of individuals in each size class was modelled on the log-scale using two normal 255 distributions (one for each size class):

$$
X_{i, t}^{>0^{+}} \sim \operatorname{Normal}\left(\lambda_{i, t}^{>0^{+}}, \sigma^{>0^{+}}\right)
$$

where $X_{i, t}$ is the log-abundance of individuals in each size class $\left(0^{+}\right.$and $\left.>0^{+}\right)$at site $\mathrm{i}$ and time t, $\lambda_{i, t}$ is the expected log-abundance and $\sigma$ is the associated process error variance. The means of the two distributions (i.e. $\lambda_{i, t}^{0^{+}}$and $\lambda_{i, t}^{>0^{+}}$) were modeled with different functional forms to account for variation in the underlying demographic process (see Grenouillet et al., 2001 for a similar approach). Specifically, the dynamic of $0^{+}$individuals was modelled as:

$$
\lambda_{i, t}^{0^{+}}=\alpha_{i}^{0^{+}}+\beta^{0^{+}} \times \frac{X^{>0^{+}}}{\log \left(S_{i, t}\right)}+\sum_{j=1}^{J} \gamma_{i, j}^{0^{+}} \times U_{j, i, t}+\log \left(S_{i, t}\right)
$$

where $\alpha^{0}{ }_{i}^{+}$is a site varying intercept, $\beta_{i}^{0^{+}}$is a density-dependent parameter reflecting the dependency of $0^{+}$individuals to the abundance of $>0^{+}$individuals at time $t$ and can be interpreted as the apparent recruitment rate (since sampling takes place after reproduction) and $S_{i, t}$ is the sampling area (offset term). Note that the recruitment rate is only 'apparent' because (1) the $>0^{+}$ size-class includes both spawners and non-spawners (reported age at maturity for females is 3-4 years for the chub, 2-3 years for the roach and 5 years and more for the barbel; Keith et al., 2011, 
270 2020) and thus also accounts for the effect of competition with non-spawners and (2) inferences

271 are based directly on the abundance of recruits (i.e. $0^{+}$individuals that successfully hatched),

272 hence not accounting for variation in the per capita reproductive investment (i.e. the number of

273 eggs laid by a given individual). A more accurate estimation of the recruitment rate could be

274 achieved using egg data together with data on spawner biomass/abundance. The parameters $\gamma_{i, j}^{0^{+}}$

275 are regression coefficients applied to the array $U_{j, i, t}$ which contains the raw and the squared

276 values of the mean and the variability of water temperatures at site $\mathrm{i}$ and time t. Thus, $\gamma_{i, j}^{0^{+}}$is a

277 vector of coefficients representing the linear and the quadratic effect of the mean and the

278 variability of water temperature on $0^{+}$abundance at each site.

The dynamic of $>0^{+}$individuals was represented using a modified version of the

stochastic Gompertz model of population growth as:

281

$$
\begin{aligned}
\lambda_{i, t}^{>0^{+}}=\alpha & \alpha_{i}^{>0^{+}}+X_{i, t-1}^{>0^{+}}+\beta_{i}^{>0+} \times \frac{X_{i, t-1}^{>0^{+}}}{\log \left(S_{i, t-1}\right)}+\delta_{i}^{>0+} \times \frac{X_{i, t-1}^{0^{+}}}{\log \left(S_{i, t-1}\right)}+\sum_{j=1}^{J} \gamma_{i, j}^{>0^{+}} \\
& \times U_{j, i, t}+\log \left(\frac{S_{i, t}}{S_{i, t-1}}\right)
\end{aligned}
$$

282 where $\alpha_{i}^{>0^{+}}$is a site varying intercept representing the intra-class productivity rate (an analog to

283 the population growth rate with values above one indicating positive productivity rates), $\beta_{i}^{>0^{+}}$

284 is a density-dependent parameter representing the competition between $>0^{+}$individuals for

285 access to resources and $\delta_{i}^{>0^{+}}$represents the transition probability between the two size classes

286 (i.e. the apparent survival rate of $0^{+}$individuals). Similar to the recruitment rate, we note here

287 that the survival rate is only 'apparent' because the $>0^{+}$size-class includes individuals in

288 different ages. This survival rate thus also accounts for the survival probability of all other size- 
289 classes. The parameters $\gamma_{i, j}^{>0^{+}}$are regression coefficients representing the linear and the

290 quadratic effects of the two temperature variables on $>0^{+}$abundance.

291 Quadratic effects were included in both dynamics to account for potential bell-shaped

292 response curves along the temperature gradient (Austin, 1999). The model was fitted to each

293 species separately, and included random site effects for all population dynamic parameters,

294 ultimately making it possible to analyze spatial patterns in the contribution of biotic and

295 temperature-related factors to the dynamic of each size-class.

Parameter estimation and model goodness of fit

298 The model was fitted to each species using Bayesian inference and weakly informative priors.

299 Site-specific parameters $\left(\alpha_{i}^{0^{+}}, \beta_{i}^{0^{+}}, \gamma_{i, j}^{0^{+}}, \alpha_{i}^{>0^{+}}, \beta_{i}^{>0^{+}}, \delta_{i}^{>0^{+}}, \gamma_{i, j}^{>0}{ }^{+}\right)$were assumed to follow

300 normal distributions with a vector of means $\boldsymbol{\mu}_{\alpha^{0}} \mu_{\beta^{0}}, \mu_{\gamma_{j} 0^{+}}, \mu_{\alpha}>0_{\beta}^{+}, \mu_{\beta^{+}}>\mu_{j}>0_{j}^{+}$,

$\left.301 \mu_{\delta}>0^{+}\right\}$and of standard deviations $\sigma_{\alpha^{0}}\left\{\sigma_{\beta^{0}}, \sigma_{\gamma_{j}{ }_{j}^{+}}, \sigma_{\alpha}>0^{+}, \sigma_{\beta}>0_{\gamma}^{+}, \sigma_{j}>0_{\delta}^{+}, \sigma_{\delta_{0}}>\right\}$.

302 The vector $\boldsymbol{\mu}$ represents the average value of the parameters across all sampling sites whereas the

303 vector $\boldsymbol{\sigma}$ represents departures from the mean and therefore the spatial variability in parameter

304 values. We used normal distributions with mean zero and standard deviations of 10 as priors for

305 all $\mu$. For $\sigma,{\sigma^{0}}^{+}$and $\sigma^{>0^{+}}$, we used half-Cauchy distributions (Gelman, 2006). For each

306 species, we generated three chains of length 11,000 with initial values in different regions of

307 parameter space and discarded the first 1,000 iterations as burn-in. Chains were sampled every

30810 iterations. Convergence was visually assessed and confirmed using the Gelman and Rubin

309 statistic with a threshold value of 1.1 (Gelman \& Rubin, 1992). Highest Posterior Density (HPD) 
310 intervals were used as 95\% credible intervals. For each parameter, differences between species

311 were assessed by computing the proportional overlap between the two posterior distributions. A

312 low overlap (threshold set to 5\% meaning that only 5\% of MCMC samples were common

313 between the two distributions) was taken as evidence that estimated parameters were different

314 between species.

315 We used posterior predictive checks (Gelman, Meng \& Stern, 1996) to assess the

316 goodness of fit of our model for the three species. Specifically, we used $\chi^{2}$ discrepancy metrics to

317 compute the posterior predictive p-value, which quantifies the extent to which the proportion of

318 samples in which the distance of observed data to the model is greater than the distance of

319 replicated data to the model. Values close to 0.5 indicate a good model fit, whereas values close

320 to 0 or 1 indicate lack of fit. Bayesian p-values were calculated regarding the log-abundance of

321 both $0^{+}$and $>0^{+}$individuals. We fitted the models using JAGS 4.3.0 (Plummer, 2003), run

322 through the R environment (R Core Team, 2019) using the packages R2jags (Su \& Yajima,

323 2013) and rjags (Plummer, 2014). The JAGS code is available in the supplementary material

324 (Appendix S2).

325

326

\section{Elasticity analyses}

327 We applied an elasticity analysis to species model outputs in order to highlight the relative

328 contribution of biotic $\left(\alpha_{i}^{0^{+}}, \beta_{i}^{0^{+}}, \beta_{i}^{>0^{+}}\right.$and $\left.\delta_{i}^{>0^{+}}\right)$and temperature-related $\left(\gamma_{i, j}^{0^{+}}\right.$and $\left.\gamma_{i, j}^{>0^{+}}\right)$

329 factors to the population dynamics of the three species following the framework developed by

330 Koons et al., (2015). Specifically, for each species, we used the median of the posterior

331 distribution of parameters obtained from the fitted model to project the log-abundance of both

332 size-classes at each site over the study period (Haridas, Tuljapurkar \& Coulson, 2009). This was

Peer] reviewing PDF | (2021:07:63205:2:0:NEW 7 Jan 2022) 
333 done by iteratively updating the parameter $\lambda_{i, t}$ for both $0^{+}$and $>0^{+}$individuals using observed

334 predictor values for the parameter for which elasticity needs to be calculated but average

335 predictor values for the other parameters. We measured the contribution of biotic and

336 temperature-related factors separately for each size-class by comparing the log-abundance

337 computed using parameter values predicted by the model $\left(\theta_{\text {ori }}\right)$ to the log-abundance computed

338 by changing each parameter value, one at a time by $10 \%\left(\theta_{\text {per }}\right.$; both the linear and the quadratic

339 terms were changed for temperature-related factors). Specifically, elasticities were computed

340 numerically as:

$$
\mathrm{e}_{\omega, \mathrm{i}, \mathrm{t}}=\frac{\theta_{\text {per,i,t }}-\theta_{\text {ori,i,t }}}{\theta_{\text {ori,i,t }}} \times \frac{1}{\delta}
$$

342 where $\theta$ is the response parameter (i.e. log-abundance of the considered size-class original and

343 perturbed) at site $\mathrm{i}$ and time $\mathrm{t}, \omega$ is the parameter of interest and $\delta$ is the proportional change in $\omega$

344 (i.e. 10\%). The mean of all $\mathrm{e}_{\omega, \mathrm{i}, \mathrm{t}}$, therefore represents the estimated elasticity of parameter $\omega$ at

345 the species level $\left(\mathrm{e}_{\omega, \mathrm{sp}}\right)$. For each parameter, differences between species were tested using

346 Wilcoxon signed-rank tests with p-values adjusted for multiple comparisons using the

347 Bonferroni correction.

348

349

Spatial patterns in the contribution of biotic and temperature-related factors

In order to establish how the contribution of biotic and temperature-related factors varied

351 spatially, we built four different linear models: an intercept-only model (null model against

352 which the other models are compared to), a model with elevation as covariate (elevation range-

353 shift model), a model with latitude as covariate (latitude range-shift model) and a model with

354 the Haversine distance (i.e. Euclidean distance accounting for the curvature of the Earth) to the 
355 geographic range center (abundant-center hypothesis model; Soberón, Townsend Peterson \&

356 Osorio-Olvera, 2018) as covariate. The three models with covariates included quadratic terms to

357 account for non-linear effects. Models were run for the eight parameters for which elasticity was

358 computed and compared using AIC (Burnham \& Anderson, 2002). For each species, further

359 details for the three covariates is provided in the supplementary material (Appendix S1; Fig. S4).

\section{Results}

362 The Bayesian population dynamics models converged well for all three species (potential scale

363 reduction factor less than 1.1 for all parameters). The posterior predictive checks revealed very

364 good model fits either for $0^{+}$or $>0^{+} \log$-abundance with Bayesian p-values close to 0.5 in all 365 cases.

\section{Global patterns}

368

369

370

371

372

373

374

375

376

Despite different life-history strategies, the large-scale ecological determinants of the population dynamics of the three species were similar, though the magnitude of effects varied across species (Fig. 2). For all species, the productivity rate of $>0^{+}$individuals suggested that populations had the potential to grow from low densities $\left(\alpha^{>0^{+}}>1\right.$; Fig. 2$)$, particularly for chub $\left(\mathrm{HPD}_{95 \%}=\right.$ $[1.42 ; 1.71])$. Furthermore, all species presented a positive recruitment rate $\left(\beta^{0^{+}}>0\right)$ as well as evidence for a regulation of the dynamic of $>0^{+}$individuals by density $\left(\beta^{>0^{+}}<0\right)$ potentially owing to competition for resources (Fig. 2). However, barbel presented a tendency for a lower recruitment rate $\left(\mathrm{HPD}_{95 \%}=[1.03 ; 2.18]\right)$ and a stronger regulation by density $\left(\mathrm{HPD}_{95 \%}=[-4.11 ;-\right.$ 5.19]) than the two other species. Chub $\left(\mathrm{HPD}_{95 \%}=[0.24 ; 0.60]\right)$ and particularly roach $\left(\mathrm{HPD}_{95 \%}\right.$ 
$377=[0.56 ; 1.11])$ also presented evidence for a positive survival rate of $0^{+}$individuals $\left(\delta^{>} 0^{+}>0\right)$

378 whereas the effect was more uncertain for barbel $\left(\mathrm{HPD}_{95 \%}=[-0.28 ; 0.46]\right.$; Fig. 2). All species

379 presented a tendency for a linear (all quadratic terms have their $\mathrm{HPD}_{95 \%}$ overlapping zero) and

380 rather positive effect of temperature-related factors on the dynamic of both $0^{+}$and $>0^{+}$

381 individuals, although with some uncertainty (Fig. 2). For instance, barbel $\left(\mathrm{HPD}_{95 \%}=[0.14\right.$;

$3820.48])$ and to a lower extent chub $\left(\mathrm{HPD}_{95 \%}=[0.04 ; 0.27]\right)$ presented evidence for a positive effect

383 of temperature variability on $0^{+}$abundances whereas for roach we rather found a positive effect

384 of average temperature on the abundance of $>0^{+}$individuals $\left(\mathrm{HPD}_{95 \%}=[0.02 ; 0.18]\right)$.

\section{Relative contribution of biotic and temperature-related factors to population dynamics}

387 Globally, the elasticity analysis indicated that the log-abundance of the three species was most

388 sensitive to changes in biotic factors acting on the dynamics of $>0^{+}$individuals than on the

389 dynamics of $0^{+}$individuals (Fig. 3). For instance, a 10\% change in the strength of density

390 dependence $\left(\beta^{>0^{+}}\right)$would, on average, induce a $10.1 \%$ decrease in the log-abundance of $>0^{+}$

391 individuals while a $10 \%$ change in the recruitment rate of $0^{+}$individuals $\left(\beta^{0^{+}}\right)$would only entail

392 a $0.9 \%$ increase in the log-abundance of $0^{+}$individuals. Temperature-related factors only had a

393 marginal contribution with the cumulative effect over both size classes only inducing a $0.7 \%$

394 change in log-population abundance on average. Yet, a number of populations presented

395 elasticity values close to 0.4 (meaning a $4 \%$ change), indicating that temperature-related factors

396 can have important local effects on the dynamic of both size-classes (Fig. 3).

397 Overall, chub was the species presenting the largest elasticities (mean=0.34, $\mathrm{SD}=0.47$ )

398 followed by roach (mean $=0.32, \mathrm{SD}=0.25)$ and then barbel (mean $=0.16, \mathrm{SD}=0.19)$. This tendency

399 was congruent and statistically significant (Wilcoxon test p-value $<0.05$ ) for most biotic 
400 parameters, except the recruitment rate, were roach presented the largest elasticity (Fig. 3).

401 Regarding temperature-related factors, although most comparisons were statistically significant,

402 the differences were anecdotal relative to biotic factors.

403

404 Spatial patterns in the contribution of biotic and temperature-related factors to population 405 dynamics

406 Despite evidence for large-scale determinants of population dynamics, the contribution of biotic

407 and temperature-related factors strongly varied depending on the spatial location of populations

408 (Fig. 4). For most factors we found that these spatial variations were mostly related to elevation

409 and less so to latitude or the distance to the geographic range center (Table 2).

410 Regardless of the species or the parameter considered, the null model was never ranked

411 as the best model (Table 2). For barbel, four out of the seven factors were related to elevation,

412 three to latitude (productivity rate, strength of density dependence and survival rate) and only

413 one to the geographic range center (recruitment rate). For chub, six factors were related to

414 elevation, two to latitude (strength of density dependence and recruitment rate) and zero to the

415 geographic range center. All parameters of roach were related to elevation.

$416 \quad$ For all species and both size-classes, we always found stronger support for a differential

417 contribution of temperature-related factors along elevation than along latitude or the distance to

418 the geographic range center (Table 2). Furthermore, the contribution of temperature-related

419 factors varied similarly along elevation for the three species and the two size-classes (Fig. 5).

420 Indeed, we mostly found negative relationships between elasticities and elevation indicating (1) a

421 rather negative effect of both factors on high elevation populations but a positive effect on low

422 elevation populations and (2) a stronger contribution of temperature variability on high elevation 
423 populations but a stronger contribution of average temperature on low elevation populations

424 (Fig. 5). Departures from this global pattern were nevertheless detected with e.g. an increasing

425 and positive contribution of average temperature on the dynamic of $>0^{+}$individuals along

426 elevation for barbel.

427 More complex spatial patterns were detected when considering the contribution of biotic

428 factors (Fig. 5). Regarding the productivity rate $\left(\mu_{\alpha}>0^{+}\right)$, the barbel presented a negative

429 relationship with latitude indicating a stronger and positive contribution of this parameter to the

430 dynamic of $>0^{+}$individuals for populations located at low latitudes whereas the opposite trend

431 was observed for chub and roach along the elevation gradient (i.e. a higher contribution for

432 populations located at high elevations). We also found evidence for a decrease in the

433 contribution of the survival rate on the dynamic of $>0^{+}$individuals $\left(\mu_{\delta}>0^{+}\right)$along elevation (for

434 roach and chub) or latitude (for barbel). Similarly, the three species presented a positive

\left.435 relationship between the strength of density dependence ${\left(\mu_{\beta}>0^{+}\right.}\right)$and either latitude (barbel and

436 chub) or elevation (roach), thus indicating a stronger negative contribution (since the parameter

437 was negative, a positive relationship indicated a trend toward zero) of this parameter in low

438 elevation populations. For the recruitment rate $\left(\mu_{\beta^{0}}{ }^{+}\right)$, while barbel presented evidence for an

439 increasing positive contribution of this parameter as the distance to the geographic center

440 increases, the two other species presented a negative relationship along latitude (for chub) or

441 elevation (for roach) indicating a lower contribution of the recruitment rate on high

442 elevation/latitude populations. 


\section{Discussion}

445 Identifying the factors driving population dynamics is paramount if we are to effectively manage

446 populations and prevent local extinction. To date, most studies have focused on explaining

447 temporal variation of single population abundances (Coulson, 2001; Koons et al., 2015), hence

448 ignoring spatial variation across populations (Frederiksen, Harris \& Wanless, 2005; Pearce-

449 Higgins et al., 2015). Here, we used length-frequency histograms and population abundance data

450 to better understand the spatial drivers of the population dynamics of three freshwater fish

451 species. Importantly, by integrating elasticity analyses into the modeling framework, we not only

452 estimate the effect of biotic and temperature-related factors on fish population dynamics, but also

453 evaluate their relative impacts (Koons et al., 2015). Despite contrasted life-histories of the three

454 species, we found that the large-scale ecological determinants of their population dynamics were

455 similar, with a stronger influence of biotic factors over temperature-related ones. Yet, the

456 contribution of the factors strongly varied depending on the location of population within

457 species' distributional ranges and appeared to vary depending on elevation, latitude and the

458 distance to the geographic range center.

459 The hierarchical structure of our modelling framework allowed us to investigate the

460 large-scale ecological determinants of population dynamics while accounting for site-specific

461 effects (Clark, 2005; Dorazio, 2016). Interestingly, we found that spatio-temporal variations in

462 the abundance of the three species were driven by similar processes and were mostly influenced

463 by factors acting on the dynamics of $>0^{+}$individuals. Specifically, $>0^{+}$abundances appeared to

464 be strongly affected by density dependence, thus suggesting that most populations are at their

465 carrying capacity and are regulated by competition between individuals for resources (Sæther et

466 al., 2008). Though the effect was less clear, the dynamics of the three species also tended to be 
467 similarly affected by temperature-related factors, with both the mean and variability of

468 temperature affecting freshwater fish population dynamics (Lawson et al., 2015). Overall, we

469 found a positive relationship between temperature variability and the population growth rate,

470 suggesting that conservation actions designed to buffer populations against environmental

471 variability could in some cases reduce population growth rate (Lawson et al., 2015). The convex

472 relationships found for the three species along the gradient of average temperature suggest that

473 abundances are higher at both extremes of the temperature gradient. While this could be

474 explained by local adaptations or the effect of other ecological processes (e.g. release of

475 competition pressures due to competing species being negatively affected at both ends of the

476 gradient), this result contrasts with both theoretical expectations (Pironon et al., 2017) and recent

477 empirical patterns (Waldock et al., 2019) showing concave relationships between population

478 abundance and temperature. An alternative explanation for these convex shapes could be that the

479 sampled populations do not cover the full distributional range of the species, implying that

480 species response curves are likely truncated (Thuiller et al., 2004). Furthermore, 95\% credible

481 intervals are rather wide suggesting some uncertainties in the estimated relationships. The similar

482 responses observed for the three species, despite contrasting life-histories, either suggest that

483 differences in traits are not strong enough to entail differences in population dynamics or that

484 other factors not accounted for in this study (e.g. habitat quality, discharge) have an

485 overwhelming influence on the observed dynamics. Such common dynamics are in line with the

486 widespread phenomenon of population synchrony, whereby populations tend to fluctuate in a

487 similar way in various taxonomic groups (Liebhold, Koenig \& Bjørnstad, 2004) including fishes

488 from French streams (Chevalier, Laffaille \& Grenouillet, 2014; Chevalier et al., 2015). 

species' ecology were apparent. For instance, chub presented a higher contribution of the

491 productivity rate to population dynamics than the two other species, suggesting that this species

492 has a greater ability to grow from low density - and therefore to recover from disturbance (Oliver 493 et al., 2015). This pattern matches well with the periodic strategy of chub that is favored in

494 predictable (e.g. seasonal) and extended environments (Winemiller, 1992). Similarly, and despite 495 the limited information contained in the data (see methods), we found a tendency toward a 496 stronger contribution of the recruitment rate for roach and chub than for barbel, a pattern in line 497 with the reported fecundities of the three species (Table 1; Kottelat \& Freyhof, 2007). The 498 populations dynamics of chub and roach also appeared to be more strongly influenced by the survival rate than for barbel. However, given data limitation, this results must be interpreted carefully as it may simply reflect the fact that barbel females tend to mature at a later stage $(\sim 5$ years) than the two other species ( 2-4 years; Keith et al., 2020). Overall, the general evidence we found for a larger contribution of biotic than temperature-related factors on the dynamics of both size-classes suggests that these species are rather controlled by deterministic processes which could be interpreted as evidence that they are unlikely to be strongly affected by future climate warming. However, density-dependence can also be an important mechanism in disturbed populations which can limit its ability to withstand climate change. For instance, if external factors suddenly change the availability of resources, an already disturbed population can become increasingly dependent on biotic control (either bottom up or top down) (Henley et al., 2000). The fact that we found strong spatial variations in the relative contribution of temperature-related factors indicates that environmental conditions can still have important

511 effects on local populations. Furthermore, the overall low contribution of temperature evidenced 
512 here could be explained by a number of factors, including a poor correlation between air and

513 water temperatures, the use of a coarse resolution not representing the conditions at the sampling

514 sites, or potential interactions with other drivers not accounted for in this study (e.g. discharge or

515 habitats).

516 Some factors displayed stronger spatial variation than others. For instance, we found

517 larger spatial variation in the contribution of biotic factors affecting the dynamics of $>0^{+}$

518 individuals (productivity rate, strength of density dependence and apparent survival rate) than for

$5190^{+}$individuals (apparent recruitment rate). The contribution of temperature variability also tended

520 to be more spatially variable than the one of average temperature. Such spatial variations have

521 been related to a number of geographic gradients including elevation (Dostálek, Rokaya \&

522 Münzbergová, 2018), latitude (Turchin \& Hanski, 1997), species thermal maximum (Jiguet et al.,

523 2010) or the distance to species' range limits (Williams, Ives \& Applegate, 2003). These

524 geographic patterns suggest that intraspecific variation in population dynamic processes may be

525 predicted from knowledge about the geographic location of populations (Sæther et al., 2008).

526 While some species seem to conform to a given geographic gradient (e.g. elevation), results are

527 not always consistent, with other species showing no patterns and sometimes even opposite

528 patterns (Dallas, Decker \& Hastings, 2017; Santini et al., 2019). These inconsistencies do not

529 necessarily mean that there is no pattern, but perhaps that the geographic gradient considered is

530 not appropriate. We here sought for evidence of two common geographic patterns: one related to

531 elevation or latitude and the other related to the distance to the geographic range center. These

532 two gradients have both theoretical and empirical underpinnings (Turchin \& Hanski, 1997;

533 Sæther et al., 2008; Pironon et al., 2017; Yañez-Arenas et al., 2020) but were never confronted to 534 date. 
For the three species we considered, most of the factors contributing to population

536 dynamics showed stronger empirical support for an elevational rather than for a distance-based

537 or latitudinal gradient. This was particularly the case regarding temperature-related factors.

538 Nonetheless, the spatial pattern was not always consistent with the range shift hypothesis (Comte

$539 \&$ Grenouillet, 2013; Comte et al., 2020). For instance, while an upward shift has been

540 documented for the three species at the trailing edge (meaning extirpations; Table 1), we

541 estimated a rather positive effect of both temperature-related factors on low-elevation

542 populations. Discrepancies were also evident at the leading edge for chub and barbel. For

543 instance, the leading edge of chub was predicted to shift upward whereas we estimated a

544 negative effect of both temperature-related factors on high-elevation populations. The opposite

545 pattern was observed for barbel, i.e. estimated downward shift but positive effect of average

546 temperature. While these discrepancies can be explained by different factors, including abiotic

547 factors not accounted for (e.g. water quality - Britton, Davies \& Pegg, 2013; river flow -

548 Bergerot \& Cattanéo, 2017), extinction debts at the trailing edge (Kuussaari et al., 2009) or

549 colonization credits at the leading edge (Rumpf et al., 2019), the dendritic structure and the flow

550 directionality of the river network that strongly constrains population dynamics (Larsen et al.,

551 2021), the way range shifts were estimated (Comte \& Grenouillet, 2013) and how population

552 dynamics were modelled (this study); they can also be explained by the fact that temperature-

553 related factors contributed little to the population dynamics of the three species. The fact that the

554 contribution of biotic and temperature-related factors varies differently along geographic

555 gradients can explain why many studies failed to find general evidence for abundance-

556 distribution patterns in natural settings (Dallas, Decker \& Hastings, 2017; Santini et al., 2019).

557 Similar to our results, other studies have shown that different demographic parameters can 
558 present opposite geographic trends, through different responses along environmental gradients; a

559 process known as demographic compensation (Csergő et al., 2017). Altogether, these results call

560 for more detailed approaches (i.e. considering different components of population dynamics

561 along with their contribution) if we are to better understand the spatial drivers of population

562 dynamics and the associated species range dynamic at large spatial scales. Moreover, although

563 we highlighted spatial gradients, the spatial factors we have considered are "indirect predictors"

564 in the sense that they do not affect species directly. They are however useful because they

565 usually correlate well with other important variables that have a direct influence on species'

566 physiology (e.g. temperature) and which are of great interest to managers and stakeholders

567 (Guisan \& Zimmermann, 2000). Therefore, instead of searching for general spatial patterns,

568 future studies should seek at identifying what are the proximal determinants of spatial variations

569 in population dynamics. Such factors have already been identified for some species. For instance,

570 water quality (Britton, Davies \& Pegg, 2013) and habitat availability (Farò, Zolezzi \& Wolter,

571 2021) have been shown to be important determinants of spatial variations in barbel's population

572 growth rate. In marine fishes, Wang, Kuo \& Hsieh (2020) have recently shown that truncated age

573 structure, warming and spatially heterogeneous temperatures can enhance population spatial

574 variability. Regarding our three studied species, population dynamics mainly varied along

575 elevation which is strongly correlated with a number of direct predictors including temperature,

576 discharge, depth or particle size of sediment.

577 This study can be expanded in different ways to improve our understanding of spatial

578 variation in population dynamics. First, our data only allowed us to discretize two size classes,

579 thus limiting our ability to go deeper into the demographic mechanisms underpinning population

580 dynamics (Bergerot \& Cattanéo, 2017). For instance, the recruitment rate can be influenced by 
581 many factors which are not considered here, such as age, maturity stage, sex ratios and size that

582 can have strong influence on the fecundity of spawning individuals and the associated

583 recruitment success (Vilizzi, Copp \& Britton, 2013). Stage structured population models

584 (Caswell, 2001) and integral projection models (Merow et al., 2014) could be used to gain

585 further insights about the drivers of population dynamics, e.g. by drawing inferences on survival

586 probabilities or reproductive rates for different age classes or individual states. These models are

587 however extremely data-demanding which may preclude their application at large spatial scales,

588 though large-scale databases are being developed (http://demography-portal.ex.ac.uk/). Despite

589 providing limited information on demographic parameters, the biodiversity monitoring data and

590 the analysis workflow we have used made it possible to gain additional insights on population

591 dynamics, compared to traditional models that only focus on population abundance without

592 accounting for size-specific differences. In this sense, our modelling framework can be seen as

593 something in between traditional population dynamic models (Keith et al., 2008) and matrix

594 population models (Caswell, 2001). Second, our modelling framework could be improved in

595 different ways. For instance, depending on the data at hand (e.g. spatial or temporal replicate),

596 one can include a state-space or N-mixture component to the Bayesian population dynamic

597 model to account for spatial (and temporal) variation in detection probability (Zipkin et al.,

598 2014). Similarly, one can imagine computing parameter elasticities and testing the effect of

599 spatial covariates directly within the Bayesian model to allow uncertainty to fully propagate

600 along the different layers of the model. We here chose not to use this approach because we built

601 on previous studies that used a similar approach as ours (Grenouillet et al., 2001; Koons et al.,

602 2015), but also because such modifications would lead to a very complicated model with an

603 associated lower interoperability and a higher computation time. Third, we only considered the 
604 effect of temperature but future studies should also consider other potentially important variables

605 (e.g. hydrology, habitat diversity) to evaluate the cumulative contribution of different abiotic

606 factors to population dynamics. Considering other abiotic factors would also make it possible to

607 account for synergistic effects that may sometimes affect populations in unexpected ways

608 (Morrongiello et al., 2021). Such effects could for instance help explain the apparent contrast

609 between a leading edge for chub predicted to shift upward but a negative effect of temperature on

610 high-elevation populations (e.g. species running out of optimal niche and slowly forced to extend

611 in potentially sub adequate environments). Fourth, the abundance data we had covered a much

612 wider gradient for elevation than for the two other spatial covariates, particularly concerning the

613 distance to the geographic range center (Fig. 3). If our populations had been more evenly

614 distributed across the whole range, perhaps the distance to the geographic range center or the

615 position along the latitudinal gradient would have had stronger effects.

616

617

\section{Conclusions}

618 Illuminating the factors driving spatial variations in population dynamics is a long-standing goal

619 in Ecology (Brown, 1984; Sæther et al., 2008). Here, we evaluated whether spatial variations in

620 the contribution of different factors affecting the population dynamics of three freshwater fish

621 species could be explained by two commonly observed biogeographical patterns: one related to

622 elevation or latitude (range-shift hypothesis) and the other related to the distance to the species

623 geographical range (abundant-center hypothesis). We found that both, biotic and abiotic factors

624 rather tended to vary along elevation or latitude providing stronger support for the range-shift

625 hypothesis. Yet, the contrasted spatial patterns highlighted here suggest that observed spatial 
626 variations in population dynamics can be the result of different processes acting in opposite ways

627 with e.g. one process (e.g. climate change) driving spatial variation in one way and another

628 process (e.g. competition for resources) driving spatial variation in another way. This dual

629 influence may partly explain why some recent studies found low evidence for geographic

630 gradients (Dallas, Decker \& Hastings, 2017). Overall, our results call for more detailed

631 approaches (considering different demographic parameters along with their contribution) if we

632 are to better understand the drivers of spatial variation in population dynamics and associated

633 abundance-distribution patterns.

634

\section{Acknowledgements}

635 We are indebted to the French Biodiversity Agency (OFB) for providing fish data.

636

\section{References}

637

638

639

640

641

642

643

644

645

646

647

Andrewartha HG, Birch LC. 1954. The distribution and abundance of animals. University of Chicago Press.

Austin MP. 1999. A Silent Clash of Paradigms: Some Inconsistencies in Community Ecology. Oikos 86:170-178. DOI: 10.2307/3546582.

Bellard C, Bertelsmeier C, Leadley P, Thuiller W, Courchamp F. 2012. Impacts of climate change on the future of biodiversity. Ecology letters 15:365-377. DOI: 10.1111/j.14610248.2011.01736.x.

Benton TG, Plaistow SJ, Coulson TN. 2006. Complex population dynamics and complex causation: devils, details and demography. Proceedings of the Royal Society of London. Series B: Biological Sciences 273:1173-81. DOI: 10.1098/rspb.2006.3495.

Bergerot B, Cattanéo F. 2017. Hydrological drivers of brown trout population dynamics in 
France. Ecohydrology 10:1-15. DOI: 10.1002/eco.1765.

649 Bivand R, Rundel C. 2018. rgeos: Interface to Geometry Engine - Open Source ('GEOS').

650 Bjørnstad ON, Grenfell BT. 2001. Noisy clockwork: time series analysis of population

651 fluctuations in animals. Science (New York, N.Y.) 293:638-643. DOI:

$652 \quad 10.1126 /$ science. 1062226.

653 Britton JR, Davies GD, Pegg J. 2013. Spatial variation in the somatic growth rates of European

654 barbel Barbus barbus: A UK perspective. Ecology of Freshwater Fish 22:21-29. DOI:

$655 \quad 10.1111 / \mathrm{j} .1600-0633.2012 .00588 . x$.

656 Brown JH. 1984. On the Relationship between Abundance and Distribution of Species. The

657 American Naturalist 124:255-279. DOI: 10.1086/284267.

658 Burnham KP, Anderson DR. 2002. Model selection and multi-model inference: a practical

659 information-theoretic approach. Springer.

660 Cappuccino N, Price PW. 1995. Population dynamics: new approaches and synthesis. San diego,

661 California, USA: Academic Press.

662 Caswell H. 2001. Matrix population models. Wiley Online Library.

663 Cattanéo F, Lamouroux N. 2002. The influence of hydrological and biotic processes on brown

664 trout (Salmo trutta) population dynamics. Canadian Journal of ... 59:12-22. DOI:

$665 \quad 10.1139 /$ f01-186.

666 Chevalier M, Comte L, Laffaille P, Grenouillet G. 2018. Interactions between species attributes

667 explain population dynamics in stream fi shes under changing climate. Ecosphere 9. DOI:

$668 \quad 10.1002 /$ ecs2.2061.

669 Chevalier M, Laffaille P, Ferdy J-B, Grenouillet G. 2015. Measurements of spatial population

670 synchrony: influence of time series transformations. Oecologia 179:15-28. DOI: 
672 Chevalier M, Laffaille P, Grenouillet G. 2014. Spatial synchrony in stream fish populations:

673 influence of species traits. Ecography 37:960-968. DOI: 10.1111/ecog.00662.

674 Clark JS. 2005. Why environmental scientists are becoming Bayesians. Ecology Letters 8:2-14.

675 DOI: $10.1111 /$ j.1461-0248.2004.00702.x.

676 Cohen J. 1960. A coefficient of agreement of nominal scales. Educational and Psychological

677 Measurement 20:37-46. DOI: 10.1177/001316446002000104.

678 Comte L, Grenouillet G. 2013. Do stream fish track climate change? Assessing distribution shifts

679 in recent decades. Ecography 36:1236-1246. DOI: 10.1111/j.1600-0587.2013.00282.x.

680 Comte L, Grenouillet G, Bertrand R, Murienne J, Bourgeaud L, Hattab T, Lenoir J. 2020.

681 BioShifts: a global geodatabase of climate-induced species redistribution over land and sea. $682 \quad$ Figshare.

683 Coulson T. 2001. Age, Sex, Density, Winter Weather, and Population Crashes in Soay Sheep.

684 Science 292:1528-1531. DOI: 10.1126/science.292.5521.1528.

685 Coulson T, Catchpole E a, Albon SD, Morgan BJ, Pemberton JM, Clutton-Brock TH, Crawley

686 MJ, Grenfell BT. 2001. Age, sex, density, winter weather, and population crashes in Soay

687 sheep. Science 292:1528-31. DOI: 10.1126/science.292.5521.1528.

688 Csergő AM, Salguero-Gómez R, Broennimann O, Coutts SR, Guisan A, Angert AL, Welk E, 689 Stott I, Enquist BJ, McGill B, Svenning JC, Violle C, Buckley YM. 2017. Less favourable 690 climates constrain demographic strategies in plants. Ecology Letters 20:969-980. DOI:

$691 \quad$ 10.1111/ele.12794.

692 Curnutt J, Pimm S, Maurer B. 1996. Population variability of sparrows in space and time. Oikos 693 76:131-144. 
694 Dallas T, Decker RR, Hastings A. 2017. Species are not most abundant in the centre of their 695 geographic range or climatic niche. Ecology Letters 20:1526-1533. DOI:

$696 \quad 10.1111 /$ ele.12860.

697 Dallas T, Pironon S, Santini L. 2020. The abundant-centre is not all that abundant: a comment to 698 Osorio-Olvera et al. 2020. bioRxiv. DOI: 10.1101/2020.02.27.968586.

699 Dorazio RM. 2016. Bayesian data analysis in population ecology: motivations, methods, and $700 \quad$ benefits. Population Ecology 58:31-44. DOI: 10.1007/s10144-015-0503-4.

701 Dostálek T, Rokaya MB, Münzbergová Z. 2018. Altitude, habitat type and herbivore damage 702 interact in their effects on plant population dynamics. PLoS ONE 13:1-18. DOI:

703 10.1371/journal.pone.0209149.

704

Engen S, Lande R, Saether BE, Bregnballe T. 2005. Estimating the pattern of synchrony in 705 fluctuating populations. Journal of Animal Ecology 74:601-611.

Engler R, Randin CF, Vittoz P, Czáka T, Beniston M, Zimmermann NE, Guisan A. 2009. Predicting future distributions of mountain plants under climate change: Does dispersal capacity matter? Ecography 32:34-45. DOI: 10.1111/j.1600-0587.2009.05789.x.

Farò D, Zolezzi G, Wolter C. 2021. How much habitat does a river need? A spatially-explicit 710 population dynamics model to assess ratios of ontogenetical habitat needs. Journal of 711 Environmental Management 286. DOI: 10.1016/j.jenvman.2021.112100.

712 Frederiksen M, Harris M, Wanless S. 2005. Interpopulation variation in demographic 713 parameters: a neglected subject? Oikos 2:209-214.

714 Froese R, Pauly D. 2021.FishBase. Available at www.fishbase.org.

715 Gelman A. 2006. Prior distributions for variance parameters in hierarchical models. Bayesian 716 Analysis 1:515-534. DOI: 10.1214/06-BA117A. 
717 Gelman A, Meng X-L, Stern H. 1996. Posterior predictive assessment of model fitness via

718 realized discrepancies. Statistica Sinica 6:733-807. DOI: 10.1.1.142.9951.

719 Gelman A, Rubin D. 1992. Inference from iterative simulation using multiple sequences.

$720 \quad$ Statistical science 7:457-511.

721 Grenouillet G, Hugueny B, Carrel GA, Olivier JM, Pont D. 2001. Large-scale synchrony and

722 inter-annual variability in roach recruitment in the Rhône River: the relative role of climatic

723 factors and density-dependent processes. Freshwater Biology 46:11-26. DOI:

724 10.1046/j.1365-2427.2001.00637.x.

725 Grøtan V, Saether B-E, Lillegård M, Solberg EJ, Engen S. 2009. Geographical variation in the

726 influence of density dependence and climate on the recruitment of Norwegian moose.

727 Oecologia 161:685-695. DOI: 10.1007/s00442-009-1419-5.

728 Guisan A, Zimmermann NE. 2000. Predictive habitat distribution models in ecology. Ecological

729 Modelling 135:147-186. DOI: 10.1016/S0304-3800(00)00354-9.

730 Guo Q, Taper M, Schoenberger M, Brandle J. 2005. Spatial-temporal population dynamics

731 across species range: from centre to margin. Oikos 1:47-57. DOI: $10.1111 / \mathrm{j} .0030-$

$732 \quad 1299.2005 .13149 . x$.

733 Haridas C V., Tuljapurkar S, Coulson T. 2009. Estimating stochastic elasticities directly from

734 longitudinal data. Ecology Letters 12:806-812. DOI: 10.1111/j.1461-0248.2009.01330.x.

735 Henley WF, Patterson MA, Neves RJ, Dennis Lemly A. 2000. Effects of Sedimentation and

736 Turbidity on Lotic Food Webs: A Concise Review for Natural Resource Managers. Reviews

737 in Fisheries Science 8:125-139. DOI: 10.1080/10641260091129198.

738 Hutchinson G. 1957. Concluding remarks. Cold Spring Harbor Symposia on Quantitative

739 Biology 22:415-427. 
740 Ibáñez B, Ibáñez I, Gomez-Aparicio L, Ruiz-Benito P, García L V, Teodoro M. 2015.

741 Contrasting effects of climate change along life stages of a dominant tree species: the 742 importance of soil-climate interactions. Diversity and Distributions.

743 Jiguet F, Devictor V, Ottvall R, Van Turnhout C, Van der Jeugd H, Lindström A. 2010. Bird

744 population trends are linearly affected by climate change along species thermal ranges.

745 Proceedings of the Royal Society of London. Series B: Biological Sciences 277:3601-8.

746 DOI: $10.1098 / \mathrm{rspb} .2010 .0796$.

747 Keith D a, Akçakaya HR, Thuiller W, Midgley GF, Pearson RG, Phillips SJ, Regan HM, Araújo

748 MB, Rebelo TG. 2008. Predicting extinction risks under climate change: coupling stochastic

749 population models with dynamic bioclimatic habitat models. Biology letters 4:560-563.

$750 \quad$ DOI: $10.1098 /$ rsbl.2008.0049.

751 Keith P, Persat H, Feunteun E, Allardi J. 2011. Les Poissons d'eau douce de France. Paris:

752 Museum National d'Histoire Naturelle.

753 Keith P, Poulet N, Denys G, CHANGEUX T, Feunteun E, Persat H. 2020. Les Poissons d'eau

754 douce de France. Paris: Muséum national d'Histoire naturelle.

755 Knouft JH. 2018. Appropriate application of information from biodiversity databases is critical

756 when investigating species distributions and diversity: a comment on Dallas et al. ().

757 Ecology Letters 21:1119-1120. DOI: 10.1111/ele.12959.

758 Koons DN, Colchero F, Hersey K, Gimenez O. 2015. Disentangling the effects of climate,

759 density dependence, and harvest on an iconic large herbivore's population dynamics.

$760 \quad$ Ecological Applications 25:956-967.

761 Kottelat M, Freyhof J. 2007. Handbook of European freshwater fishes. Publications Kottelat 762 Cornol. 
763 Kuussaari M, Bommarco R, Heikkinen RK, Helm A, Krauss J, Lindborg R, Öckinger E, Pärtel

764 M, Pino J, Rodà F, Stefanescu C, Teder T, Zobel M, Steffan-Dewenter I. 2009. Extinction

765 debt: a challenge for biodiversity conservation. Trends in Ecology and Evolution 24:564-

766 571. DOI: $10.1016 /$ j.tree.2009.04.011.

767 Larsen S, Comte L, Filipa Filipe A, Fortin MJ, Jacquet C, Ryser R, Tedesco PA, Brose U, Erős

768 T, Giam X, Irving K, Ruhi A, Sharma S, Olden JD. 2021. The geography of metapopulation

769 synchrony in dendritic river networks. Ecology Letters 24:791-801. DOI:

$770 \quad 10.1111 /$ ele. 13699.

771 Lawson CR, Vindenes Y, Bailey L, van de Pol M. 2015. Environmental variation and population

772 responses to global change. Ecology Letters 18:724-736. DOI: 10.1111/ele.12437.

773 Liaw A, Wiener M. 2002. Classification and Regression by randomForest. R News 2:18-22.

774 Liebhold AM, Koenig W, Bjørnstad O. 2004. Spatial synchrony in population dynamics. Annual

775 Review of Ecology, Evolution and Systematics 35:467-490. DOI:

776 10.2307/annurev.ecolsys.34.011802.30000018.

777 McLachlan G, Peel D. 2004. Finite mixture models. John Wiley \& Sons.

778 Merow C, Dahlgren JP, Metcalf CJE, Childs DZ, Evans MEK, Jongejans E, Record S, Rees M,

779 Salguero-Gómez R, Mcmahon SM. 2014. Advancing population ecology with integral

$780 \quad$ projection models: A practical guide. Methods in Ecology and Evolution 5:99-110. DOI:

$781 \quad$ 10.1111/2041-210X.12146.

782 Mills CA, Mann RHK. 1985. Environmentally-induced fluctuations in year-class strength and

783 their implications for management. Journal of Fish Biology 27:209-226. DOI:

$784 \quad 10.1111 / \mathrm{j} .1095-8649.1985 . t b 03243 . x$.

785 Mills SC, Oliver TH, Bradbury RB, Gregory RD, Brereton T, Kühn E, Kuussaari M, Musche M, 
786

787

788

789

790

791

792

793

794

795

796

797

798

799

800

801

802

803

804

805

806

807

808

Roy DB, Schmucki R, Stefanescu C, van Swaay C, Evans KL. 2017. European butterfly populations vary in sensitivity to weather across their geographical ranges. Global Ecology and Biogeography 26:1374-1385. DOI: 10.1111/geb.12659.

Morrongiello JR, Horn PL, Ó Maolagáin C, Sutton PJH. 2021. Synergistic effects of harvest and climate drive synchronous somatic growth within key New Zealand fisheries. Global Change Biology 27:1470-1484. DOI: 10.1111/gcb.15490.

Nicholson AJ. 1957. The self-adjustment of populations to change. Cold Spring Harbor Symposia on Quantitative Biology 22:153-173.

Nunn a. D, Cowx IG, Frear P a., Harvey JP. 2003. Is water temperature an adequate predictor of recruitment success in cyprinid fish populations in lowland rivers? Freshwater Biology 48:579-588. DOI: 10.1046/j.1365-2427.2003.01033.x.

Oliver TH, Heard MS, Isaac NJB, Roy DB, Procter D, Eigenbrod F, Freckleton R, Hector A, Orme CDL, Petchey OL, Proença V, Raffaelli D, Suttle KB, Mace GM, Martín-López B, Woodcock BA, Bullock JM. 2015. Biodiversity and Resilience of Ecosystem Functions. Trends in Ecology and Evolution 30:673-684. DOI: 10.1016/j.tree.2015.08.009.

Parmesan C, Yohe G. 2003. A globally coherent fingerprint of climate change impacts across natural systems. Nature 421:37-42. DOI: 10.1038/nature01286.

Pearce-higgins JW, Ockendon N, Baker DJ, Carr J, White EC, Almond REA, Amano T, Bertram E, Bradbury RB, Bradley C, Butchart SHM, Doswald N, Foden W, Gill DJC, Green RE, Sutherland WJ, Tanner EVJ. 2015. Geographical variation in species' population responses to changes in temperature and precipitation. Proceedings of the Royal Society B: Biological Sciences 282:20151561. DOI: 10.1098/rspb.2015.1561.

Pearce-Higgins JW, Ockendon N, Baker DJ, Carr J, White EC, Almond REA, Amano T, 
809 Bertram E, Bradbury RB, Bradley C, Butchart SHM, Doswald N, Foden W, Gill DJC,

810 Green RE, Sutherland WJ, Tanner EVJ. 2015. Geographical variation in species’ population

811 responses to changes in temperature and precipitation. Proceedings of the Royal Society B:

812 Biological Sciences 282:20151561. DOI: 10.1098/rspb.2015.1561.

813 Pecl GT, Araújo MB, Bell JD, Blanchard J, Bonebrake TC, Chen IC, Clark TD, Colwell RK,

814 Danielsen F, Evengård B, Falconi L, Ferrier S, Frusher S, Garcia RA, Griffis RB, Hobday

815 AJ, Janion-Scheepers C, Jarzyna MA, Jennings S, Lenoir J, Linnetved HI, Martin VY,

816 McCormack PC, McDonald J, Mitchell NJ, Mustonen T, Pandolfi JM, Pettorelli N, Popova

817 E, Robinson SA, Scheffers BR, Shaw JD, Sorte CJB, Strugnell JM, Sunday JM, Tuanmu

818 MN, Vergés A, Villanueva C, Wernberg T, Wapstra E, Williams SE. 2017. Biodiversity

819 redistribution under climate change: Impacts on ecosystems and human well-being. Science $820 \quad 355$. DOI: $10.1126 /$ science.aai9214.

821 Peterson AT, Soberón J, Pearson RG, Anderson RP, Martínez-Meyer E, Nakamura M, Araújo 822 MB. 2011. Ecological Niches and Geographic Distributions. Princeton: Princeton University Press. DOI: 10.23943/princeton/9780691136868.003.0003.

824 Piffady J, Souchon Y, Capra H, Parent E. 2010. Quantifying the effects of temperature and flow 825 regime on the abundance of $0+$ cyprinids in the upper River Rhone using Bayesian 826 hierarchical modelling. Freshwater Biology 55:2359-2374. DOI: 10.1111/j.1365827 2427.2010.02453.x.

828 Pironon S, Papuga G, Villellas J, Angert AL, García MB, Thompson JD. 2017. Geographic

829 variation in genetic and demographic performance: new insights from an old 830 biogeographical paradigm. Biological Reviews 92:1877-1909. DOI: 10.1111/brv.12313.

831 Plummer M. 2003. JAGS: A program for analysis of Bayesian graphical models using Gibbs 
832

833

834

835

836

837

838

839

840

841

842

843

844

845

846

847

848

849

850

851

852

853

854

sampling. In: Hornik K, Leisch F, Zeileis A eds. Proceedings of the 3rd International Workshop on Distributed Statistical Computing (DSC 2003). Vienna, Austria,. DOI: 10.1.1.13.3406.

Plummer M. 2014.rjags: Bayesian graphical models using MCMC. Available at http://cran.rproject.org/package $=$ rjags

Poulet N, Beaulaton L, Dembski S. 2011. Time trends in fish populations in metropolitan France: insights from national monitoring data. Journal of Fish Biology 79:1436-1452. DOI: 10.1111/j.1095-8649.2011.03084.x.

R Core Team. 2019.R: A Language and Environment for Statistical Computing. Available at https://www.r-project.org/

Radchuk V, Turlure C, Schtickzelle N. 2013. Each life stage matters: the importance of assessing the response to climate change over the complete life cycle in butterflies. The Journal of animal ecology 82:275-85. DOI: 10.1111/j.1365-2656.2012.02029.x.

Roy C, McIntire EJB, Cumming SG. 2016. Assessing the spatial variability of density dependence in waterfowl populations. Ecography 39:942-953. DOI: 10.1111/ecog.01534.

Rumpf SB, Hülber K, Wessely J, Willner W, Moser D, Gattringer A, Klonner G, Zimmermann NE, Dullinger S. 2019. Extinction debts and colonization credits of non-forest plants in the European Alps. Nature Communications 10:1-9. DOI: 10.1038/s41467-019-12343-x.

Sæther B, Lillegård M, Grøtan V, Drever MC, Engen S, Nudds TD, Podruzny KM. 2008. Geographical gradients in the population dynamics of North American prairie ducks. Journal of Animal Ecology 77:869-882. DOI: 10.1111/j.1365-2656.2008.01424.x.

Sagarin RD, Gaines SD, Gaylord B. 2006. Moving beyond assumptions to understand abundance distributions across the ranges of species. Trends in Ecology and Evolution 21:524-530. 
DOI: $10.1016 /$ j.tree.2006.06.008.

856 Santini L, Pironon S, Maiorano L, Thuiller W. 2019. Addressing common pitfalls does not

857 provide more support to geographical and ecological abundant-centre hypotheses.

858 Ecography 42:696-705. DOI: 10.1111/ecog.04027.

859 Soberón J, Townsend Peterson A, Osorio-Olvera L. 2018. A comment on "Species are not most

860 abundant in the centre of their geographic range or climatic niche." bioRxiv:1-7. DOI:

$861 \quad 10.1101 / 266510$.

862 Su Y-S, Yajima M. 2013.R2jags: A Package for Running jags from R. Available at http://cran.r863 project.org/package $=$ R2jags

864 Thuiller W, Brotons L, Araújo MB, Lavorel S. 2004. Effects of restricting environmental range

865 of data to project current and future species distributions. Ecography 2:165-172.

866 Turchin P, Hanski I. 1997. An empirically based model for latitudinal gradient in vole population 867 dynamics. The American Naturalist 149:842-874.

868 Vilizzi L, Copp GH, Britton JR. 2013. Age and growth of European barbel Barbus barbus

869 (Cyprinidae) in the small, mesotrophic River Lee and relative to other populations in

$870 \quad$ England. Knowledge and Management of Aquatic Ecosystems. DOI: $10.1051 / \mathrm{kmae} / 2013054$.

872 Waldock C, Stuart-Smith RD, Edgar GJ, Bird TJ, Bates AE. 2019. The shape of abundance 873 distributions across temperature gradients in reef fishes. Ecology Letters 22:685-696. DOI: 10.1111/ele.13222.

875 Wang JY, Kuo TC, Hsieh C hao. 2020. Causal effects of population dynamics and environmental 876 changes on spatial variability of marine fishes. Nature Communications 11. DOI:

$877 \quad 10.1038 / \mathrm{s} 41467-020-16456-6$. 
878 Williams C, Ives A, Applegate R. 2003. Population dynamics across geographical ranges: time879 series analyses of three small game species. Ecology 84:2654-2667.

880 Winemiller K. 1992. Life-history strategies and the effectiveness of sexual selection. Oikos $881 \quad 63: 318-327$.

882 Winemiller KO, Rose KA. 1992. Implications for population regulation. Fisheries (Bethesda) $883 \quad 49: 2196-2218$.

884 Yañez-Arenas C, Martín G, Osorio-Olvera L, Escobar-Luján J, Castaño-Quintero S, Chiappa885 Carrara X, Martínez-Meyer E. 2020. The Abundant Niche-centroid Hypothesis: Key Points 886 About Unfilled Niches and the Potential Use of Supraspecfic Modeling Units. Biodiversity 887 Informatics 15:92-102. DOI: 10.17161/bi.v15i2.13218.

888 Zipkin E, Thorson J, See K, Lynch H. 2014. Modeling structured population dynamics using 889 data from unmarked individuals. Ecology 95:22-29.

890 


\section{Figure 1}

\section{Analyses workflow}

Analyses workflow describing (first column) how length-frequency histograms were used to discriminate the two size-classes and obtain abundance data for each size-class for all sampling operations and (second column) how abundance data were used to extract population dynamics parameters, perform the elasticity analysis and investigate the spatial patterns in the contribution of biotic and abiotic factors to the population dynamics of the three species. 
Discriminating $0+$ and $>0+$ individuals

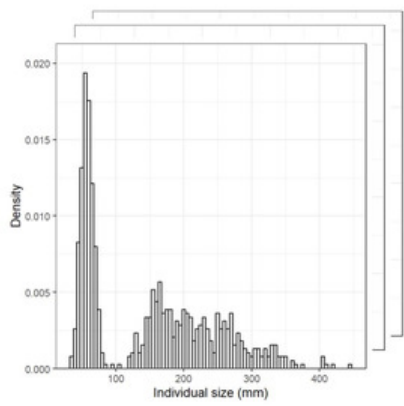

(x 20)

EM algorithm

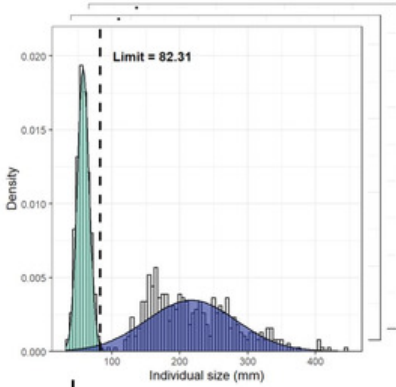

Individual status $(0+$ or $>0+)$

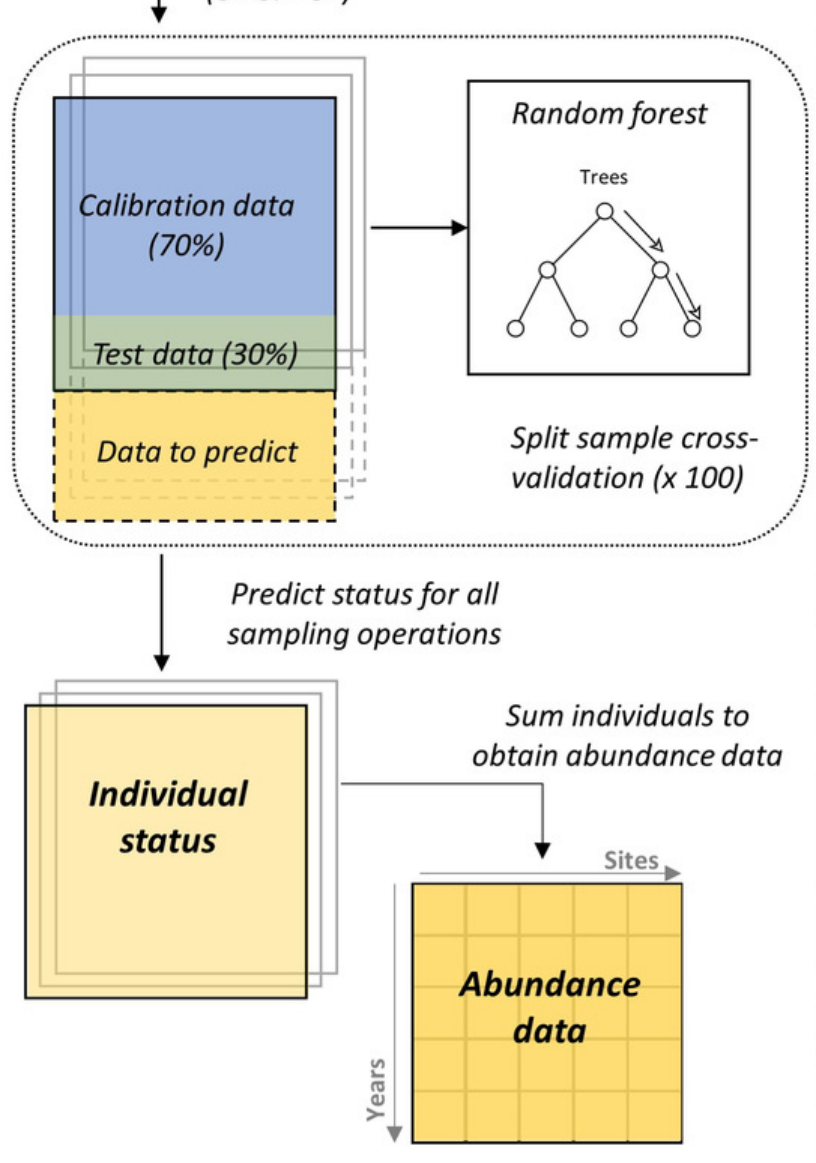

\section{Analyzing population dynamics}

Full dataset

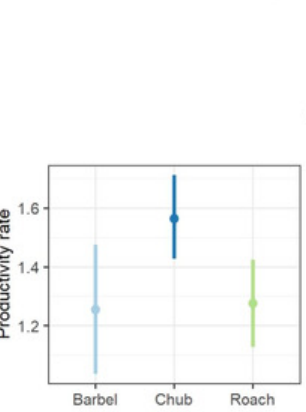

Posterior distributions

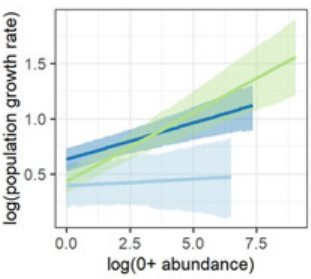

Elasticity analysis Koons et al., 2015

Range shift

hypothesis

$$
\begin{aligned}
& \text { Parameter elasticity } \sim \text { Latitude + Latitude }{ }^{2}
\end{aligned}
$$

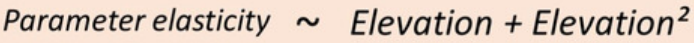

$$
\begin{aligned}
& \text { Parameter elasticity } \sim \text { Distance }+ \text { Distance }^{2}
\end{aligned}
$$
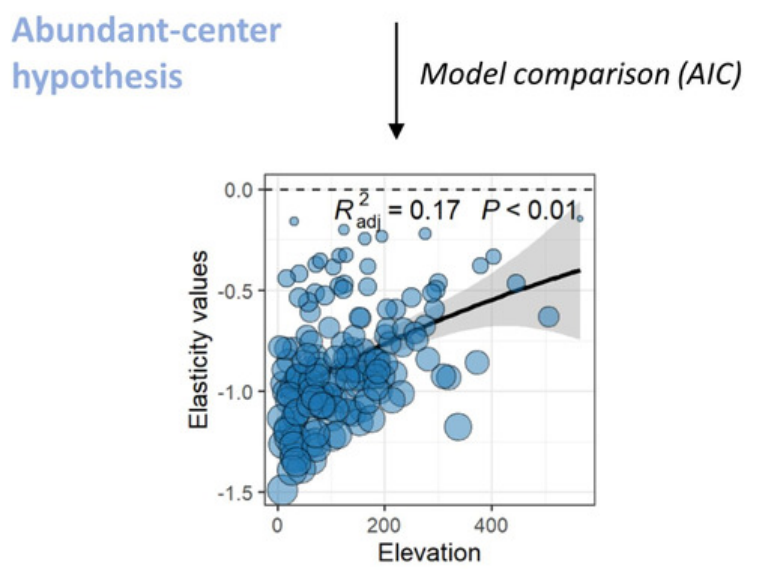


\section{Figure 2}

Posterior summary of model parameters

Posterior summary of model parameters (small-size panels with dots representing the median of the posterior distribution and the vertical line representing the associated 95\% credible interval; horizontal dashed line point to the zero value) and corresponding relationships (large-size panels with lines representing the median of the posterior distribution and shaded areas representing the associated 95\% credible interval) for the three species and the two size classes. The first column (except the first panel) highlights the effect of biotic ( <!--[if !msEquation]--> <!--[if !vml]--> <!--[endif]--><!--[endif]-->) and abiotic ( <!--[if !msEquation]--> <!--[if !vml]--> <!--[endif]--><!--[endif]-->) factors on the abundance of $0^{+}$individuals whereas the second column (and the first panel of the first column) highlights the effect of biotic ( <!--[if !msEquation]--><!--[if !vml]--> <!--[endif]-><!--[endif]-->, <!--[if !msEquation]--> <!--[if !vml]--> <!--[endif]--><!--[endif]-->) and abiotic ( $<$ !--[if !msEquation]--> <!--[if !vml]--> <!--[endif]--><!--[endif]-->) factors on the growth rate ( $<$ !--[if !msEquation]--> <!--[if !vml]--> <!--[endif]--><!--[endif]-->)) of $>0^{+}$ individuals. Differences between model parameters were tested by computing the proportional overlap between posterior distributions (ns $>5 \%$ overlap, $*<5 \%$ overlap, $* *<0.01 \%$ overlap, $* * *<0.001 \%$ overlap). 

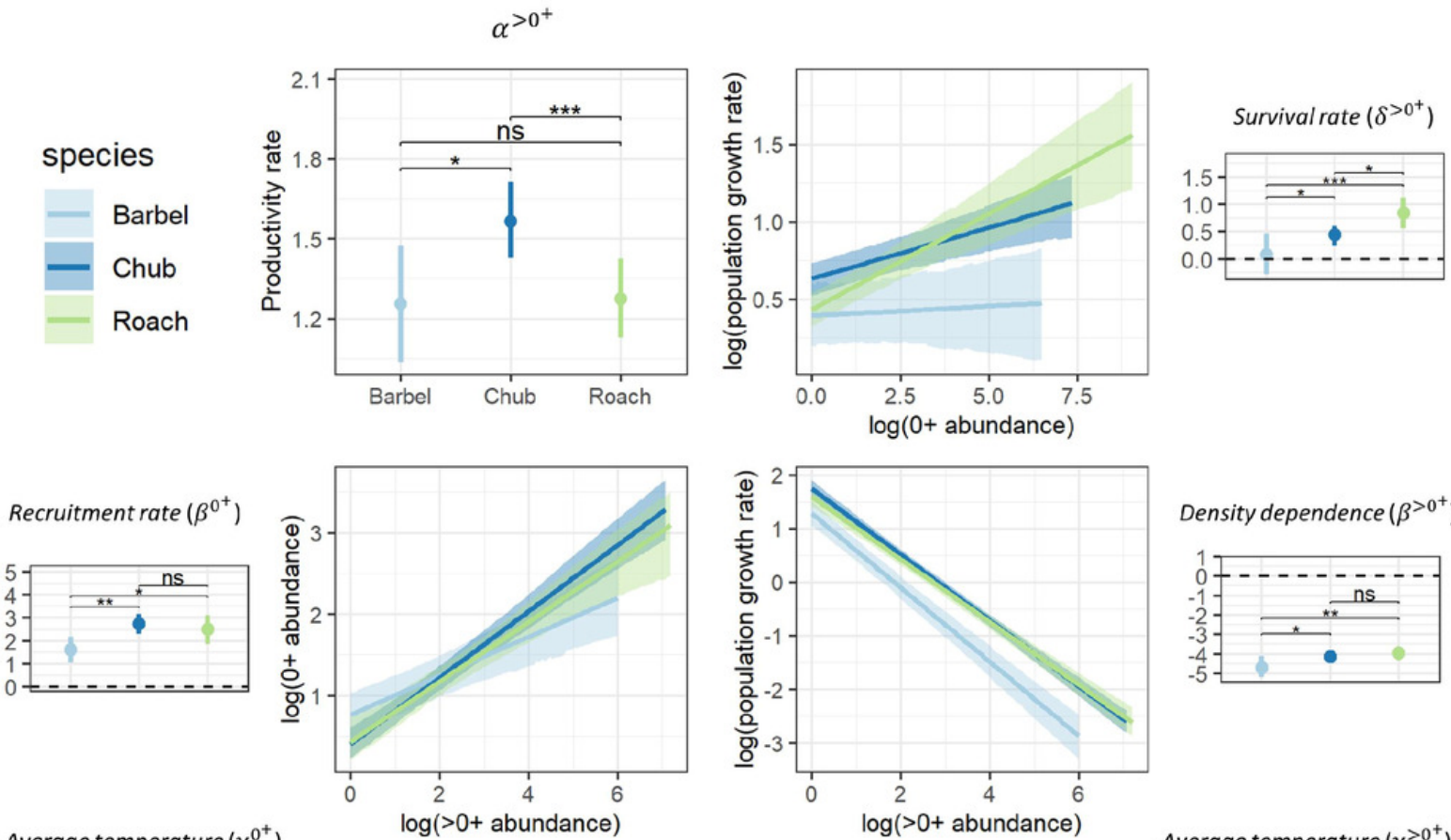

Density dependence $\left(\beta^{>0^{+}}\right)$

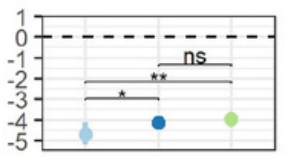

Average temperature $\left(\gamma^{0^{+}}\right)$
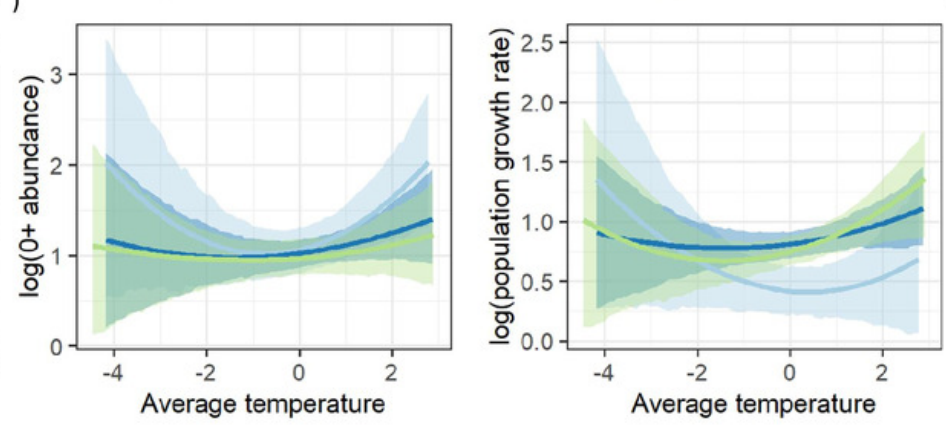

Average temperature $\left(\gamma^{>0^{+}}\right)$
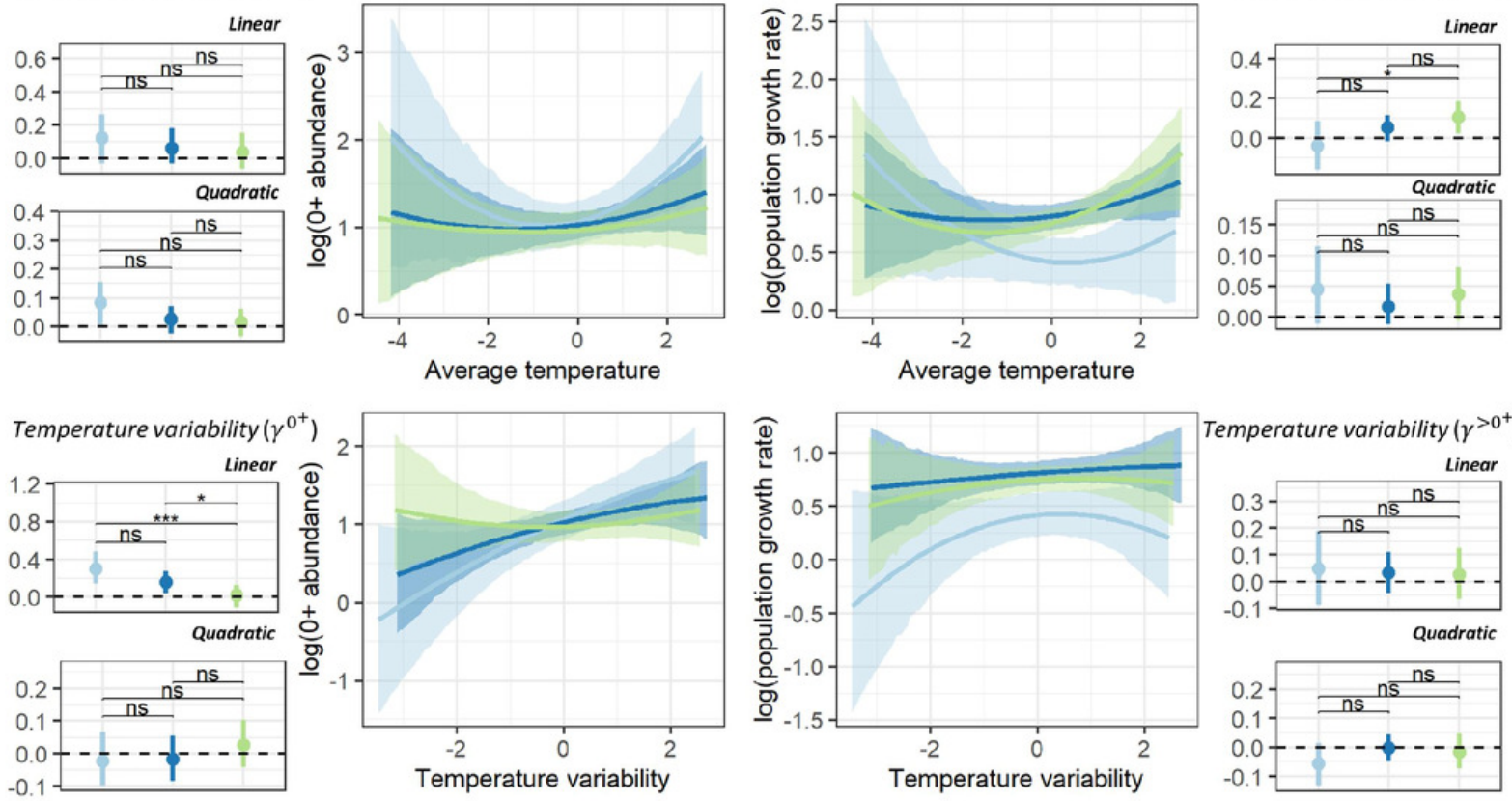


\section{Figure 3}

Boxplots representing site-specific elasticities on log-abundances

Boxplots representing site-specific elasticities on log-abundances of $0^{+}$or $>0^{+}$individuals to a $10 \%$ proportional change in the value of coefficients associated to biotic and abiotic factors for the three species with negative values pointing to a decrease in population abundance. Dots represent the average elasticity for a given site. The horizontal dashed line points to the zero value. Grey zones show coefficients affecting the dynamic of $0^{+}$individuals whereas white zones show coefficients affecting the dynamic of $>0^{+}$individuals. For temperaturerelated factors, both the linear and the quadratic coefficients were changed when calculating elasticities in order to obtain one elasticity value for each variable. Note that a boxplot overlapping zero does not mean that there is no effect but that the positive effect of the variable on some populations is counterbalanced by the negative effect of that variable on other populations. 


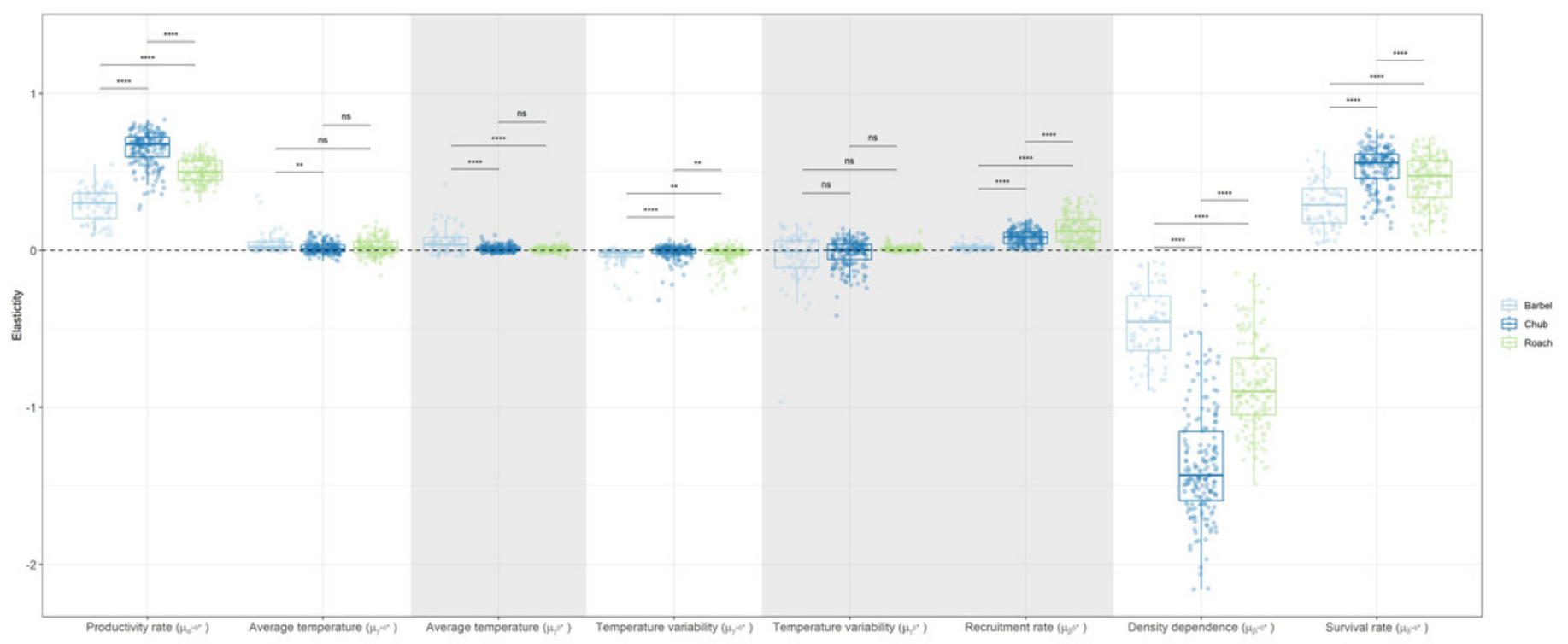




\section{Figure 4}

Spatial variation in the contribution of biotic and abiotic factors

Spatial variation in the contribution of biotic and abiotic factors to the population dynamic of the three species. Species are in lines while coefficients are in columns. Each point represents a population with colors corresponding to the estimated elasticity. The background surface represents elevation. Maps on grey background show coefficients affecting the dynamic of $0^{+}$individuals while the other maps show coefficients affecting the dynamic of $>0^{+}$individuals. Note that the color scale is different in each panel.

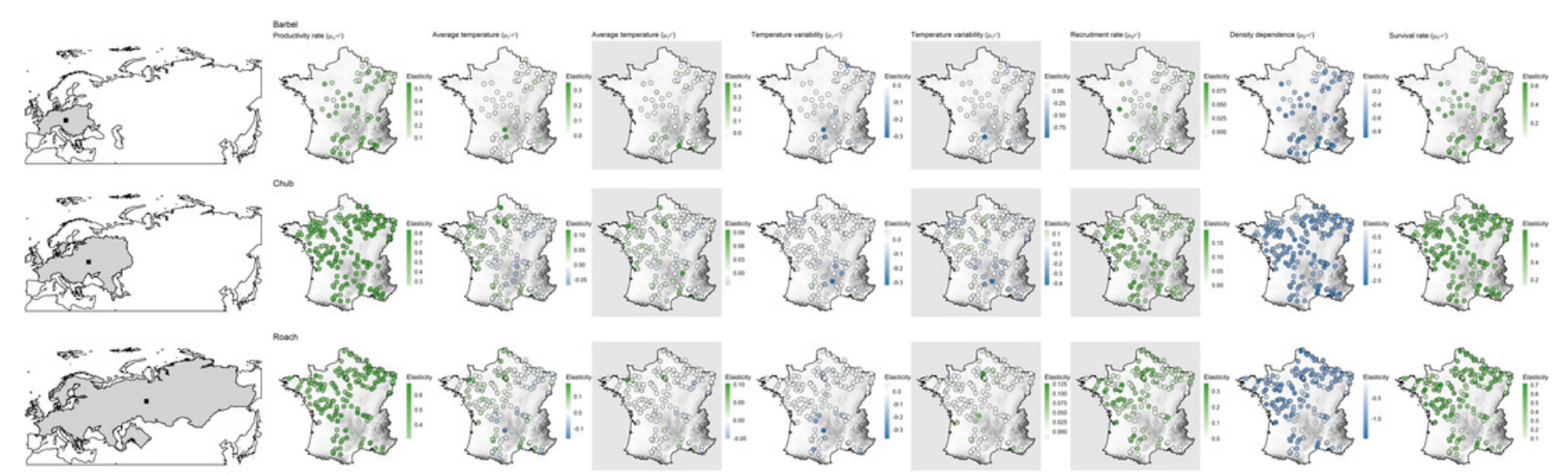




\section{Figure 5}

Spatial patterns in the contribution of biotic and abiotic factors

Spatial patterns in the contribution of biotic and abiotic factors to the population dynamics of the three species as a function of the distance to the geographic range center, latitude or elevation. Only relationships of the most supported models are displayed. In each panel, points represent elasticity values for a given population with size proportional to the corresponding absolute value and colors indicative of the sign of the value (green=positive; blue=negative). For each panel, the adjusted $\mathrm{R}^{2}$ is provided. Likelihood ratio tests were all significant ( $p<0.01$ in all cases). Grey zones show coefficients affecting the dynamic of $0^{+}$ individuals whereas white zones show coefficients affecting the dynamic of $>0^{+}$individuals. 


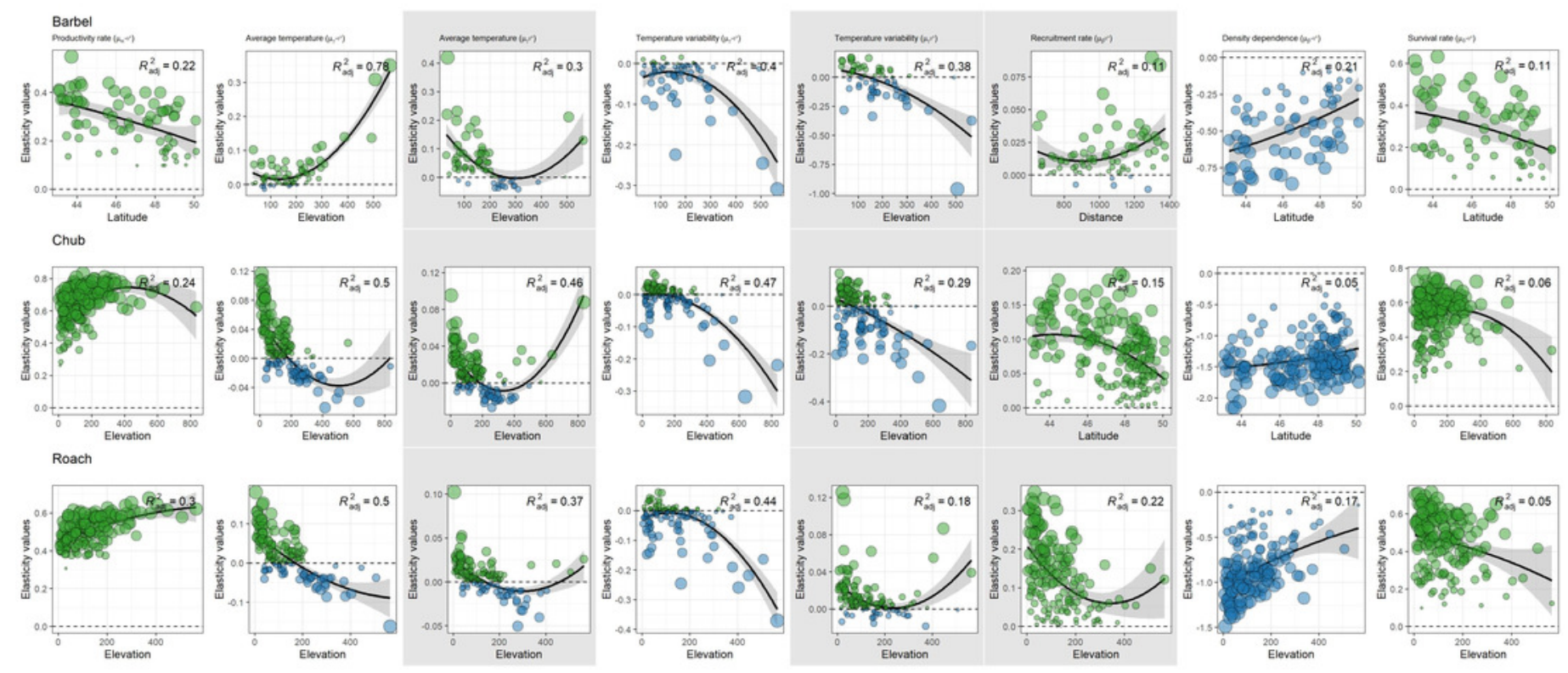




\section{Table $\mathbf{1}$ (on next page)}

Life-history attributes and range shifting patterns

Life-history attributes and range shifting patterns along the altitudinal gradient for the three freshwater species. Values were taken from various sources (Froese and Pauly 2002, Kottelat and Freyhof 2007, Comte and Grenouillet 2013) . 
Table 1. Life-history attributes and range shifting patterns along the elevational gradient for the three freshwater fish species. Values were taken from various sources (Froese and Pauly 2002, Kottelat and Freyhof 2007, Comte and Grenouillet 2013).

\begin{tabular}{cccc}
\hline & Roach & Chub & Barbel \\
Fecundity & 50,000 & 125,000 & 10,000 \\
Body length $(\mathrm{mm})$ & 275 & 400 & 500 \\
Lifespan (years) & 14 & 16 & 20 \\
Critical thermal maximum $\left({ }^{\circ} \mathrm{C}\right)$ & 39.00 & 38.00 & 32.00 \\
Range size $\left(\mathrm{km}^{2}\right)$ & $19,522,376$ & $7,126,749$ & $2,782,586$ \\
Shift trailing edge $(\mathrm{m} / \mathrm{yr})$ & 0.022 & 0.054 & 0.115 \\
Shift leading edge $(\mathrm{m} / \mathrm{yr})$ & -0.873 & 1.542 & -4.311 \\
Shift centroid $(\mathrm{m} / \mathrm{yr})$ & 0.266 & 0.209 & -0.125 \\
Strategy & Opportunistic & Periodic & Equilibrium \\
\hline
\end{tabular}

2 References

3 Comte, L. and Grenouillet, G. 2013. Do stream fish track climate change? Assessing distribution $4 \quad$ shifts in recent decades. - Ecography (Cop.). 36: 1236-1246.

5 Froese, R. and Pauly, D. 2002. FishBase. - World Wide Web Electron. Publ. www.fishbase.org.

6 Kottelat, M. and Freyhof, J. 2007. Handbook of European freshwater fishes. - Publications $7 \quad$ Kottelat Cornol. 


\section{Table 2 (on next page)}

Results of model selection

Results of model selection performed on the different populations dynamic parameters for the three species. For coefficients and $\mathrm{R}^{2}$ values of the most supported model; see Figure 5. 
Table 2. Results of model selection performed on the different populations dynamic parameters for the three species. For coefficients and $\mathrm{R}^{2}$ values of the most supported model; see Figure 5.

\begin{tabular}{|c|c|c|c|c|c|c|c|}
\hline Species & Factor name & Parameters & $\begin{array}{l}\text { AIC null } \\
\text { model }\end{array}$ & $\begin{array}{c}\text { AIC } \\
\text { elevation } \\
\text { model }\end{array}$ & $\begin{array}{l}\text { AIC distance } \\
\text { model }\end{array}$ & $\begin{array}{l}\text { AIC latitude } \\
\text { model }\end{array}$ & $\begin{array}{c}\text { Most supported } \\
\text { model }\end{array}$ \\
\hline \multirow{8}{*}{ Barbel } & \multirow{2}{*}{ Average temperature } & $\mu_{\gamma}>0^{+}$ & -193.66 & -298.93 & -190.39 & -189.93 & Elevation \\
\hline & & $\mu_{\gamma}{ }^{0}+$ & -155.03 & -178.19 & -158.49 & -163.56 & Elevation \\
\hline & \multirow{2}{*}{ Temperature variability } & ${ }_{\gamma}^{\mu}>0^{+}$ & -200.43 & -235.13 & -196.56 & -197.42 & Elevation \\
\hline & & $\mu_{\gamma^{0}}+$ & -50.54 & -82.55 & -47.24 & -46.72 & Elevation \\
\hline & Productivity rate & $\mu_{\alpha}>0+$ & -115.69 & -116.98 & -118.07 & -131.06 & Latitude \\
\hline & Recruitment rate & $\mu_{\beta^{0+}}$ & -363.13 & -359.26 & -369.61 & -363.16 & Distance \\
\hline & $\begin{array}{l}\text { Strength of density } \\
\text { dependence }\end{array}$ & $\mu_{\beta}>0+$ & -8.38 & -8.43 & -12.25 & -23.19 & Latitude \\
\hline & Survival rate & $\mu_{\delta}>0+$ & -62.54 & -62.64 & -65.39 & -68.88 & Latitude \\
\hline \multirow{8}{*}{ Chub } & \multirow{2}{*}{ Average temperature } & $\mu_{\gamma}>0^{+}$ & -682.02 & -800.46 & -692.26 & -679.58 & Elevation \\
\hline & & ${ }_{\gamma}{ }^{0^{+}}$ & -860.57 & -967.08 & -876.46 & -858.79 & Elevation \\
\hline & \multirow{2}{*}{ Temperature variability } & $\mu_{\gamma}>0^{+}$ & -587.89 & -698.38 & -584.56 & -586.36 & Elevation \\
\hline & & $\mu_{\gamma^{0}}+$ & -361.64 & -419.49 & -358.73 & -359.85 & Elevation \\
\hline & Productivity rate & $\mu_{\alpha}>0+$ & -278.44 & -323.66 & -281.23 & -283.25 & Elevation \\
\hline & Recruitment rate & $\mu_{\beta} 0+$ & -571.99 & -573.06 & -584.55 & -597.6 & Latitude \\
\hline & $\begin{array}{l}\text { Strength of density } \\
\text { dependence }\end{array}$ & $\mu_{\beta}>0+$ & 131.5 & 124.65 & 135.05 & 124.34 & Latitude \\
\hline & Survival rate & $\mu_{\delta}>0+$ & -206.12 & -214.43 & -204.24 & -206.63 & Elevation \\
\hline \multirow{5}{*}{ Roach } & \multirow{2}{*}{ Average temperature } & ${ }_{\gamma}^{\mu}>0^{+}$ & -455.68 & -558.56 & -458.19 & -455.13 & Elevation \\
\hline & & $\mu_{\gamma^{0}}+$ & -797.41 & -866.15 & -806.89 & -795.79 & Elevation \\
\hline & \multirow{2}{*}{ Temperature variability } & ${ }_{\gamma}^{\mu}>0^{+}$ & -424.75 & -511.74 & -421.17 & -428.4 & Elevation \\
\hline & & $\mu_{\gamma^{0}}+$ & -755.84 & -784.64 & -757.28 & -752.73 & Elevation \\
\hline & Productivity rate & $\mu_{\alpha}>0+$ & -357.98 & -411.26 & -367.68 & -355.22 & Elevation \\
\hline
\end{tabular}




\begin{tabular}{ccccccc}
\hline $\begin{array}{c}\text { Recruitment rate } \\
\text { Strength of density } \\
\text { dependence }\end{array}$ & $\mu_{\beta} 0+$ & -299.57 & -335.09 & -295.97 & -299.99 & Elevation \\
$\begin{array}{c}\mu_{\beta}>0+ \\
\text { Survival rate }\end{array}$ & $\mu_{\delta}>0+$ & -143.24 & 32.43 & 62.13 & 49.66 & Elevation \\
\hline
\end{tabular}

